\title{
Agent Based Modeling on Organizational Dynamics of Terrorist Network
}

\author{
Bo Li, Duoyong Sun, Renqi Zhu, and Ze Li \\ College of Information System and Management, National University of Defense Technology, Changsha 410072, China \\ Correspondence should be addressed to Bo Li; libonudt@gmail.com
}

Received 30 April 2015; Revised 31 August 2015; Accepted 11 October 2015

Academic Editor: Aura Reggiani

Copyright (C) 2015 Bo Li et al. This is an open access article distributed under the Creative Commons Attribution License, which permits unrestricted use, distribution, and reproduction in any medium, provided the original work is properly cited.

\begin{abstract}
Modeling organizational dynamics of terrorist network is a critical issue in computational analysis of terrorism research. The first step for effective counterterrorism and strategic intervention is to investigate how the terrorists operate with the relational network and what affects the performance. In this paper, we investigate the organizational dynamics by employing a computational experimentation methodology. The hierarchical cellular network model and the organizational dynamics model are developed for modeling the hybrid relational structure and complex operational processes, respectively. To intuitively elucidate this method, the agent based modeling is used to simulate the terrorist network and test the performance in diverse scenarios. Based on the experimental results, we show how the changes of operational environments affect the development of terrorist organization in terms of its recovery and capacity to perform future tasks. The potential strategies are also discussed, which can be used to restrain the activities of terrorists.
\end{abstract}

\section{Introduction}

A key aspect of studying terrorist network is to investigate the organizational dynamics and the mechanism by which its structure grows and changes over time [1]. Due to the networked connection between terrorists, network analysis methods provide a powerful way to study the organizational structure. The interplay between topology and dynamics in complex networks is a fundamental problem, which has not been widely studied [2]. Individual behavior and network ties mutually influence each other [3]. For studying terrorist organization, it is important to find out how the terrorists behave in performing tasks and how the activities affect the organizational dynamics $[4,5]$. On the other hand, terrorist network is usually not a complete picture due to the inherent difficulties in obtaining data. It shows only those links that have been publicly disclosed $[6,7]$. Hence, using computational experimentation to obtain insight into the dilemma of terrorist network dynamics is valuable.

Many reported empirical works have studied the structural characteristics of terrorist network using Social Network Analysis (SNA) [8-11]. They provide both qualitative and quantitative results with empirical data and are helpful in understanding the relational structure and finding key elements (individual, subgroup, etc.). However, it is consensus that terrorist organization is dynamic and far more complicated than structural network $[12,13]$. Dynamic network anal$y$ sis (DNA) and metanetwork are used to model the complex organizational structure and individual interaction [14]. In order to analyze the operational and evolutional dynamics of terrorist network, agent based modeling/simulation ( $\mathrm{ABM} / \mathrm{S})$ is introduced to model the autonomous agents and their interactions [15-17]. This method is effective in understanding the complicated evolution of system derived from agent interaction with rich results of simulation experiments [18, 19]. Lots of models are proposed to describe the terrorist behavior [20-22]. Based on the ABM method, changes detection of organizational network characteristics [20], network coevolution of social and geospatial dimensions [22], and dynamics between networks [15] are investigated. These reported works studied the terrorist network from different perspectives and provided useful results to investigate how the terrorists act and its influence on the organizational dynamics.

However, there are two limitations in current reported studies. Firstly, the terrorist network should be analyzed 


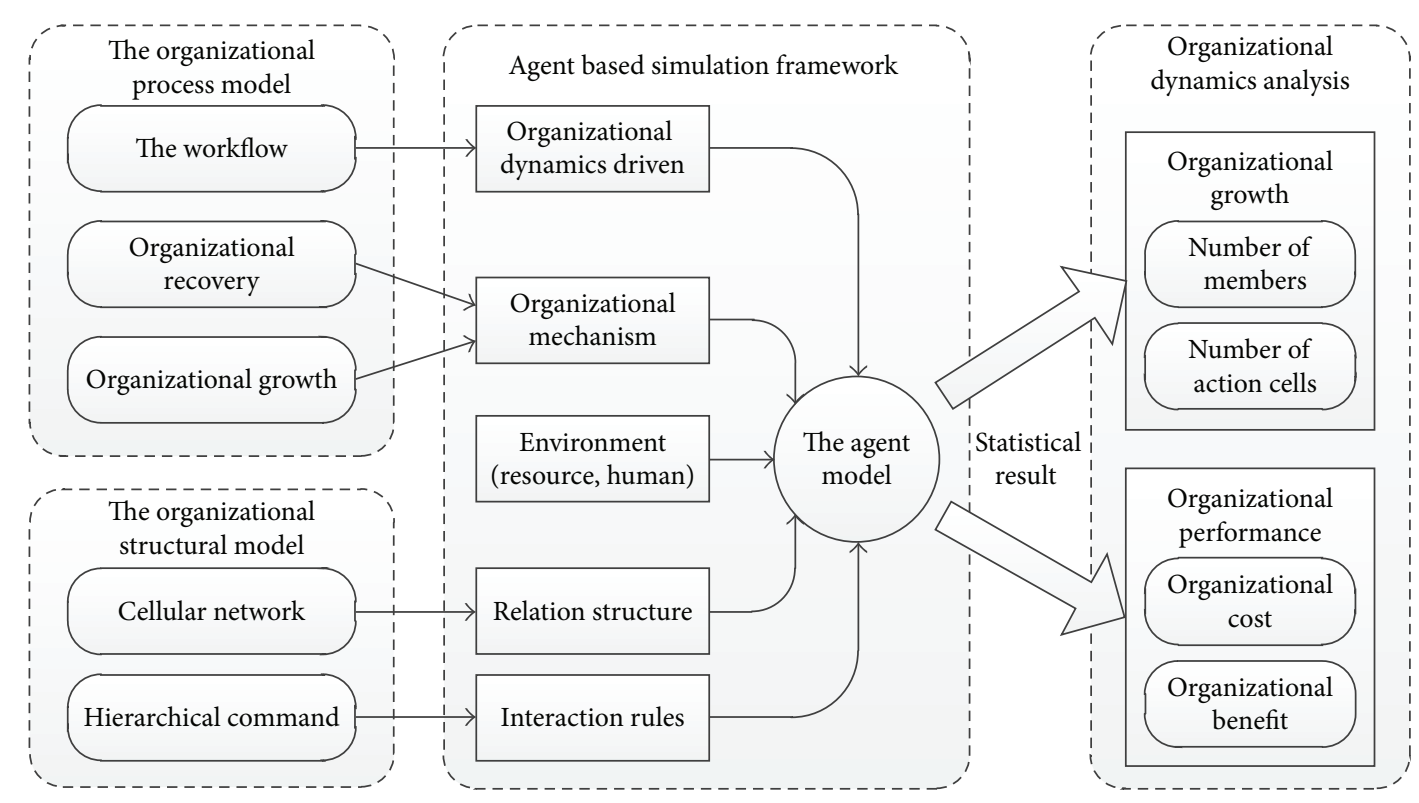

FIGURE 1: The systematic framework of the research on organizational dynamics of terrorist network.

with the dynamic organizational process. Terrorists take actions based on not only the relational network, but also the established operational process. The relational network evolves under different conditions and makes the analysis of SNA ineffective [23]. The other limitation is that the mechanism of recovery in studying the dynamics or intervention strategies has not been fully considered. The resilience of terrorist network provides the organization with the ability of survival and growth. In fact, understanding how to suppress the recovery of terrorist network is more important than the identification of key nodes for developing strategies of counterterrorism [24].

In this paper, we study the organizational dynamics of terrorist network by employing the computational experimentation method. The rest of the paper is organized as follows. Section 2 describes the overall research framework of this paper. Section 3 gives the model of hierarchical cellular network to describe the functional terrorist network. The actions based on this organizational structure are also defined. Section 4 proposed the organizational process model to describe the organizational dynamics. The mechanisms of task workflows, organizational recovery, and organizational growth are proposed to model the operational processes. In addition, the resilience of terrorist network is incorporated into the model by the recovery of organizational elements. Section 5 gives the evaluations of organizational performance. Both costs and benefits are included to analyze the performance. In Section 6, by employing the ABM method, the terrorist network is simulated in both open and limited environments, and the impacts of different factors are tested under various dynamic scenarios. With the results, we show how the terrorist network works as an organization and what elements affect the performance. The potential strategies are also discussed, which exhibits the potential applications for public security department. Section 7 concludes the paper.

\section{Research Framework}

In order to study the organizational dynamics of terrorist network, the agent based modeling is employed to construct the computational framework of the terrorist organization. As shown in Figure 1, the framework consists of four components. (1) The agent based simulation framework is used to model the complex interaction between the terrorists within the organization. (2) The organizational structural model is used to describe the relation between the terrorists and the corresponding command structure. (3) The organizational process model includes the workflow, the organizational mechanisms of recovery, and growth. This model provides the organizational driven and behavioral mechanism. (4) The organizational dynamics analysis includes the organizational performance and growth. The performance reflects the functional dynamics during the organizational activities, and the growth represents the structural dynamics.

The ABS framework provides the tool to model the complex interaction behavior between terrorists and to observe the organizational dynamics. The organizational models are added to the framework as the elements of agent based modeling on terrorist organization. Cellular network and hierarchical command relation are used to describe the specific structure and relation in terrorist network. The process model consists of three mechanisms, the workflow, the recovery, and the growth. The workflow generates organizational driven and individual behaviors, and it gives the general rules of organizational activities. The recovery mechanism and the growth mechanism give two rules of organizational 


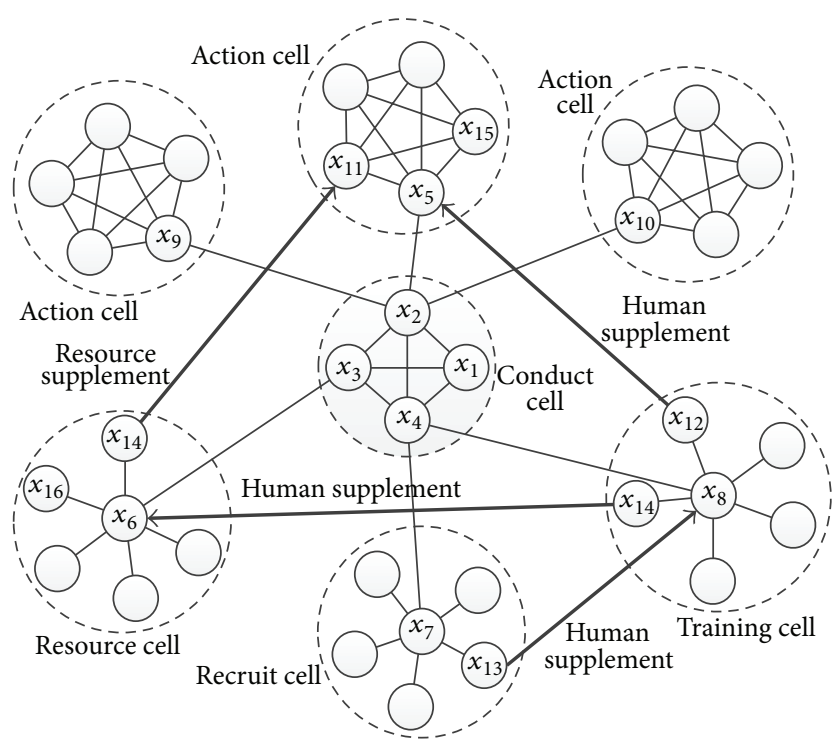

FIgURE 2: Organizational structural model of terrorist network.

activities in specific situations. As the simulation time goes on, the statistical results are changing, and the organizational dynamics analysis is carried out based on the results captured in the system.

\section{The Organizational Structural Model of Terrorist Network}

Terrorist network is different from social network in two aspects, (a) cellular groups as basic activity units and (b) hierarchical command structure. Terrorists operate according to this hybrid structure, which makes the network do not correspond to a particular kind of network model [25]. Based on the description of terrorist network in [26], a theoretical terrorist network is shown in Figure 2. The characteristics can be understood from three aspects, the cellular network structure, the hierarchical command structure, and the individual actions based on the network.

3.1. Cellular Network Structure. It has been reported that cellular network is the most suitable structure to describe terrorist organization $[27,28]$. It usually consists of many cell groups (or subgroups), which are the basic active units to perform tasks $[29,30]$. As shown in Figure 2, the cells are cohesive structure of a set of connected individuals who cooperate to perform the task. The reason for terrorists to adopt this network topology is structural compartmentalization [26], which is a trade-off between efficiency and security.

Different network structures are adopted by the cells to fulfil the diverse functional requirements [31]. In this model, we hypothesize that all the cells' structures conform to corresponding network models. Action cells have the structure of fully connected network for frequent communication between the members in it, and so is the conduct cell. The structures of recruit cells and resource cells conform to star network, which are helpful for the cells to perform task (resource acquirement and human recruitment) widely and covertly. We also use star network here to depict the structure of training cell because of the function of the cell, training the terrorists singly as a "factory," where the terrorists are the products and are transferred to the other cells for human supplement.

The terrorist network can be regarded as a graph $G=$ $(N, E)$, where $N$ represents the set of agents (terrorists) and $E$ is the set of all the relations in the network. We hypothesize that the network only includes the member of the organization, which means the agents in the environment are not considered. Only the formal relations are included in this model and the informal relations, such as social relation, are not considered in this paper. The cells can be regarded as subgroups of $G$. In this model, five types of cell are considered according to their function in the organization, and the notations are listed in Table 1, as well as the explanations. Each cell contains a node set (as $N_{\mathrm{AC}}$ in $G_{\mathrm{AC}}$ ) and an edge set (as $E_{\mathrm{AC}}$ in $G_{\mathrm{AC}}$ ) which is the set of all the relations between the nodes in the cell. As there is more than one action cell, we use $n_{\mathrm{ac}}$ to represent the number of action cells.

\subsection{Hierarchical Command Structure}

3.2.1. Role of Terrorist and Type of Relation. Recall that terrorist network is different from social network in organizational activities. As an organization, the roles of terrorists are diverse and the relational type depends on their roles. Based on the cellular network structure, we define two types of roles in the model, the cell leader and the cell member. The role is defined as a property of agent and the definitions are as follows.

Cell leader (denoted as Role $_{l}$ ) is the leader of a cell. It organizes the activities of the cell members and connects to the superior cell for organizational command.

Cell member (denoted as Role ${ }_{m}$ ) is the member of a cell. It performs the specific activities in task process.

We also define two types of relations in this model, the peer-to-peer relation and the superior-subordinate relation.

Peer-to-peer relation (denoted as $\mathrm{Rel}_{\mathrm{pp}}$ ) is the type of link between the agents with the same role.

Superior-subordinate relation (denoted as $\mathrm{Rel}_{\mathrm{ss}}$ ) is the type of link between the agents with different roles.

As the terrorist organization has hierarchical structure, we give the assumptions used in this model:

(1) The type of the relation between the members in the same cell is $\mathrm{Rel}_{\mathrm{pp}}$, and the type of the relation between them and the cell leader is $\mathrm{Rel}_{\mathrm{ss}}$.

(2) The member of the conduct cell is the superior of the other cells, which means the relations between them and the leaders of the other cells are $\mathrm{Rel}_{\mathrm{ss}}$.

(3) There is no relation between the cells leaders; that is, a cell leader cannot interact directly with another cell leader.

These assumptions are given based on the characteristics of terrorist organization and empirical research. According to the definition and described cellular network in Section 3.1, the hierarchical structure of terrorist network is fixed to some 
TABLE 1: The notations of the cells in the cellular network.

\begin{tabular}{lc}
\hline Notation & Explanations \\
\hline$G_{\mathrm{AC}}$ & Action cell, and $G_{\mathrm{AC}}=\left(N_{\mathrm{AC}}, E_{\mathrm{AC}}\right) \subset G$ \\
$G_{\mathrm{RC}}$ & Resource cell, and $G_{\mathrm{RC}}=\left(N_{\mathrm{RC}}, E_{\mathrm{RC}}\right) \subset G$ \\
$G_{\mathrm{Co}}$ & Conduct cell, and $G_{\mathrm{Co}}=\left(N_{\mathrm{Co}}, E_{\mathrm{Co}}\right) \subset G$ \\
$G_{\mathrm{TC}}$ & Training cell, and $G_{\mathrm{TC}}=\left(N_{\mathrm{TC}}, E_{\mathrm{TC}}\right) \subset G$ \\
$G_{\mathrm{Re}}$ & Recruit cell, and $G_{\mathrm{Re}}=\left(N_{\mathrm{Re}}, E_{\mathrm{Re}}\right) \subset G$ \\
$G_{\mathrm{AC}}^{i}$ & The $i_{\text {th }}$ action cell, and $G_{\mathrm{AC}}^{i}=\left(N_{\mathrm{AC}}^{i}, E_{\mathrm{AC}}^{i}\right) \subset G$ \\
\hline
\end{tabular}

extent. The conduct cell is barely changed and the roles of the members are specified. The leaders in the other cells are designated by the superior in the conduct cell, which is to some extent fixed as well.

3.2.2. Intercell Hierarchical Structure. The command relation between cells represents inherently hierarchies between functional compartments. As illustrated in Figure 2, the tasks are operated by the conduct cell with the instructions sent to the other cells. Firstly, the conduct cell sends missions to the action cells that then take actions required to perform the tasks. When the conduct cell receives the feedback of human and resource requirements, it passes human and resource supplements to the training cell and resource cell separately. This hierarchical command structure makes the core of organization able to coordinate the members for an overall goal and maintain their own agendas. Note that the orders are transmitted by the individuals in cells, because the cell is not a real entity, but an organizational form of group members.

3.2.3. Intracell Hierarchical Structure. Decentralization at tactical level is due to the difficulty of real-time command and control within a large clandestine cellular network [26]. Cell leaders usually have freedom of tactical decision-making and action based on local condition, which produces intracell hierarchies and self-organization. As shown in Figure 2, leaders of functional cells $\left(x_{5}, x_{6}, \ldots, x_{10}\right)$ are receivers of the assigned missions. They organize the actions of other members in cells to complete tasks. Take action cell (where $x_{5}$ stays) as an example; $x_{5}$ receives a mission from the superior cell (conduct cell); then, it evaluates the requirements based on the condition of the action cell and sends the feedback to the superior cell. During the action period, $x_{11}$ is in charge of receiving resource from the resource cell and acts under the command of $x_{5}$ because it is the only one that communicates with the superior cell. Even in the core cell, the members $\left(x_{2}, x_{3}, x_{4}\right)$ are under the command of the cell leader $\left(x_{1}\right)$ who is either the leader of the organization or the only one that connects to the superior leader.

\section{The Organizational Process Model of Terrorist Network}

The organizational process model is proposed to describe the operational mechanism of terrorist network. First, the agent model is given, and the actions are defined as a set of available actions. Then, the response of agent in different mechanism is given. The organizational process model can be understood as the interactional rule of agent [17].

4.1. The Agent Model. The system considers a population of agents (terrorists) that continually act as the model progresses. As a terrorist organization, the individual behaviors and attributes are complicated. For clarity, we only consider the following attributes which are related to the organizational dynamics in this model.

Role. This is the role of agent in the cell. At the beginning, the leader of a cell is assigned and can be identified by the individual structure. Once the leader of a cell is lost, a new leader will be generated in the cell, and this will be discussed in the recovery mechanism.

Age. This is the length of time that an agent stays in the network.

Resource. This is the attribute which re-presents if an agent holds resource.

Cell Type. This is the type of the cell which the agent belongs to.

The actions are limited by the role and the cell type of agent, which means that agents have different candidate action set according to their position in the organization. The actions used in the model are defined as follows.

Requirement Passing. The requirement for resource or human is passed from the source agent to the target agent. This behavior is defined as $\operatorname{ReP}_{i, j}$, which represents that the requirement is passed from agent $i$ to agent $j$. The cost of passing a requirement is Cost $_{\mathrm{ReP}}$.

Resource Transferring. The required resource is transferred by terrorists through established channels (solid arrows in Figure 2). The element transferring behavior is defined as $\operatorname{Tra}_{i, j}$, where $i$ and $j$ are the terrorists transferring the element.

Moving. The agent moves from one cell to another cell for human supplement. This behavior is denoted as $\mathrm{Mo}_{i}$, and $i$ is the agent. There are some differences between the resource transferring and the moving. Agent remains in the resource cell and it links to the required cell after resource is transferred. Once an agent moves to a new cell, it would not connect to the original cell, which means the other cell cannot directly send the human requirement to the training cell, but it can send the resource requirement to the resource cell as long as the link exists.

Building a Link. This action is taken when a link is needed between two agents, and it is denoted as $\mathrm{BuL}_{i, j}$, where $i$ and $j$ are the agents who built the relation. As there are two types of links, the newly built link depends on the situation and the roles of the two agents, which will be discussed in the following organizational mechanism. 
TABLE 2: The candidate action set of an agent in terrorist network.

\begin{tabular}{lcc}
\hline & Role $_{l}$ & Role $_{m}$ \\
\hline Action cell & ReP, BuL & ReP, Tra, BuL \\
Resource cell & ReP, BuL, Res & ReP, Tra, BuL, Res \\
Conduct cell & ReP & ReP, BuL \\
Training cell & ReP, BuL & Mo, BuL, Train, ReP \\
Recruit cell & ReP, BuL, Rec & Mo, BuL, Rec, ReP \\
\hline
\end{tabular}

Recruitment. Recruitment (denoted as Rec) is performed by the members of recruit cell, and it is the only way to generate new member of terrorist network. We use $P_{\text {Recruit }}$ to denote the probability of successful recruitment and Cost $_{\text {recruit }}$ to represent the cost of one recruit.

Training. The new members will take certain time in training before they are assigned to a cell, and this action is denoted as $\operatorname{Train}_{i}$. The time of training is denoted as $\sigma_{\text {Training, }}$, and the cost is Cost $_{\text {training. }}$.

Resource Acquirement. The resources are acquired by the members of resource cell. We assume that the resource in this model contains kinds of needs for performing a task. The probability of resource acquirement is denoted as $P_{\text {Resource}}$, and the cost is denoted as Cost resource $_{\text {. This action is }}$ represented as Res.

The candidate action set of an agent is shown in Table 2 .

4.2. Task Workflow. The purpose of terrorist organization is to produce terror events as much as possible, and we simplify the event to a task in this model. The requirement of a task is human and resource and they are simplified as agents and resource. The general workflow of terror organization is modeled as the following four steps.

Step 1 (generating task). The task is generated by the cell leader of action cell. If an action cell is not operating any task, a new task will be created by the cell leader. Each task, $\varphi$, requires amount of resource and agents, which can be denoted as $\varphi$ (resource) and $\varphi$ (agent), respectively, representing the number of resources and agents required to fulfill a task.

Step 2 (generating requirement). The requirement is evaluated by the cell leader, and the element requirements will be sent by the agents in the cell. Assuming the size of action cell $G_{\mathrm{AC}}^{i}$ is $\left|N_{\mathrm{AC}}^{i}\right|$, then the required number of agents is

$$
N_{\text {Requirement }}=\varphi(\text { agent })-\left|N_{\mathrm{AC}}^{i}\right| \text {, }
$$

where $N_{\text {Requirement }}$ is the number of generated human requirements. The number of required resources is $\varphi$ (resource). The processes of human supplement and resource supplement are different. The human requirement will be directly sent to the superior, and for the resource, the leader will interact with all the members. If there is a member connecting to the resource cell, the requirement will be sent to the member; otherwise, it will be sent to the superior.

Step 3 (agent response). After the requirements are sent, the agent who receives the message will process the requirement based on its role and relation. Figure 3 shows the response mechanism of an agent to a requirement. The agent interacts with the other agent and it can get the information about the other agent. In this response process, the type of the link built between two members in different cells is $\operatorname{Re}_{\mathrm{pp}}$.

Step 4 (task execution). Once the requirements are fulfilled, the action cell will launch an event, and this is done by the cell leader of action cell. The activity circle of action cell can be illustrated as Figure 4. We hypothesize that the members will be lost in performing the task. The probability for each member to be arrested is denoted as $P_{\text {arrest }}$, which depends on the efficiency of counterterror department.

4.3. Organizational Recovery Mechanism. The recovery process of terrorist network is the key mechanism for organization to survive. Resilience is a dynamic process, associated with systems that persist and perform their primary tasks under pressure from exogenous shocks [32]. We do not consider the case of large-scale attack to the terrorist network and focus on the normal consumption during the operational process (a member can also be lost if he changes his mind, which may happen because of the decay of his faith in the organization. In order to focus on the organizational dynamics, we hypothesize that the members will not be lost because of the belief issue). The loss in the task concerns two types of cells, the action cell and the resource cell. The recovery process is triggered after a task is performed. Our hypothesis is that the recovery mechanism comprises two behaviors:

(1) Check the leader of the action cell. If the leader of the action cell is lost, a new leader will be generated from the remaining members. The selection rule is based on the attribute Age; that is, the agent who stays the longest in the cell will be designated as the new leader. This is because when an individual stays longer in the organization, it usually has the richest experience (expertise, knowledge, etc.) which is the most important characteristic of an action leader.

(2) After that, the new leader tries to build a new link to the superior cell with the probability $P_{\text {reconnect }}$. The type of the newly built link is $\mathrm{Rel}_{\mathrm{ss}}$. Then, the recovery action is finished.

Figure 5 displays the overall recovery process of an action cell. It can be found that the recovery mechanism of the organization is partly finished by the organizational operational process.

Resource cell also has recovery mechanism as the member may be lost in the process of performing a task. In the model, we only consider the operational consumption and hypothesize that the member is only lost when the agent in 


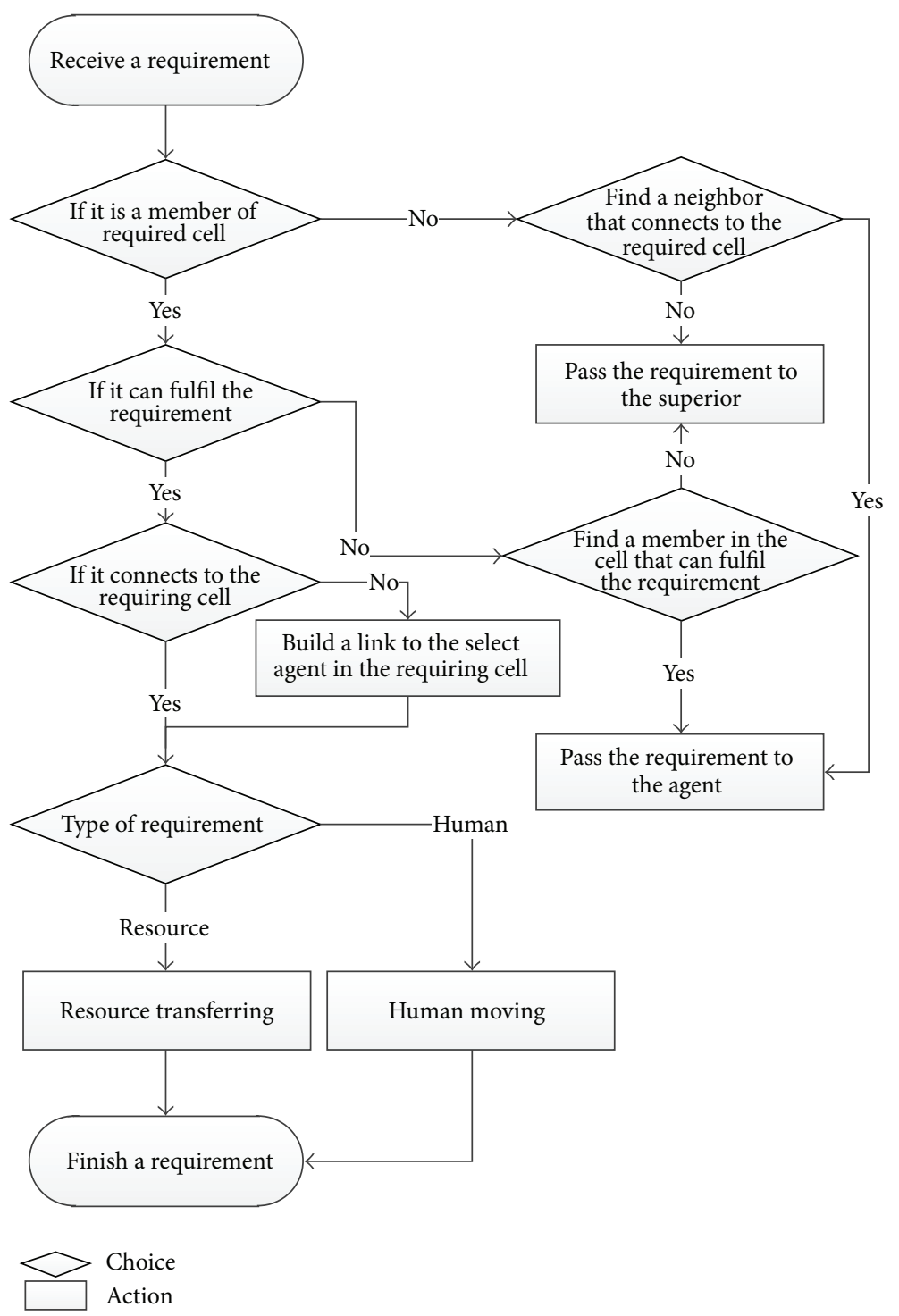

FIGURE 3: The response mechanism of agent to a requirement.

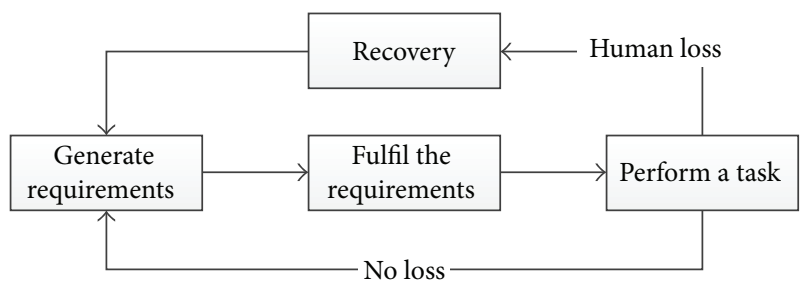

FIGURE 4: The activity circle of action cell.

action cell who links to it is arrested. The recovery mechanism of resource cell is triggered by the event that a member is lost. When a member is lost, then a human requirement is generated by the cell leader.

As illustrated in Figure 6, if member $x_{6}$, who is in the action cell and communicates with the resource sender $x_{5}$, is arrested, then $x_{5}$ is lost too. The leader of resource cell $x_{1}$ then sends human requirement to the conduct cell for supplement so as to maintain functional completeness. Even though some members are lost, the resource cell can also acquire resource, but the efficiency is lower than the complete cell.

4.4. Organizational Growth Mechanism. The launched events lead to organizational growth, and the corresponding increase in size leads to faster production of new events [33]. The more frequent the terrorist acts, the faster the network grows. Events and social influence promote the appeal of organization and recruitment of new militants [12]. For this consideration, we assume that new action cell will be generated after certain tasks are finished, and a threshold $\sigma_{\text {Task }}$ is used as the trigger of the organizational growth. The steps of growth can be modeled as follows.

Step 1 (leader requirement). A human requirement is generated and assigned to the member in the conduct cell who is in charge of action cell. 


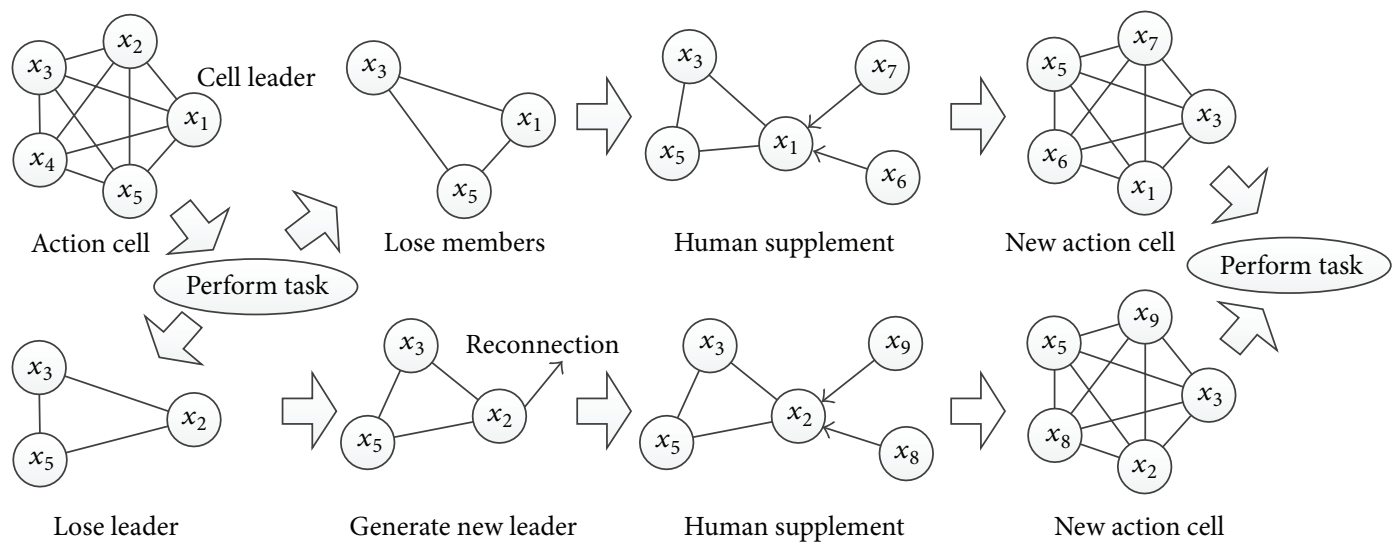

FIGURE 5: The recovery process of action cell.

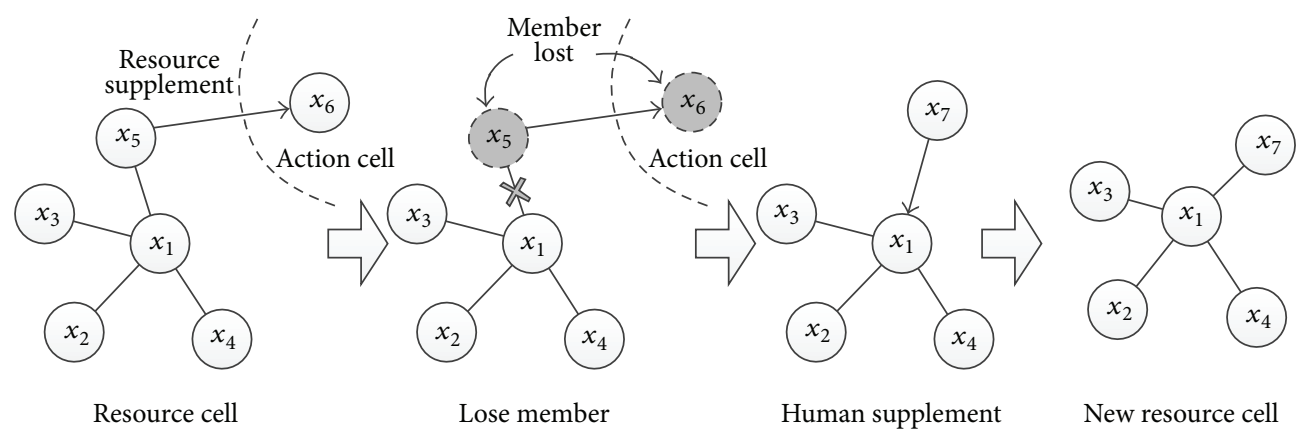

FIgURE 6: The recovery mechanism of resource cell.

Step 2 (leader designation). After the target agent moving to the new cell, it is assigned as the leader of the new action cell. In this process, the role of the agent is changed from a member of the training cell to the leader of the new cell.

Step 3 (cell formation). Although the newly built action cell has only one agent, it can be performed as a cell, which means it can be assigned a task and generate the human and resource requirements and send it to the other agents. The complete action cell would form across the organizational task flow.

The mechanism of organizational growth is shown in Figure 7 . When the tasks performed by action cells reach a threshold $\sigma_{\text {Task }}$, the network grows and establishes a new action cell. First, the leader of the new cell $\left(x_{2}\right)$ is assigned by the operational leader $\left(x_{1}\right)$ in conduct cell. Secondly, requirement of human supplement is sent by the new leader. Thirdly, the members are transferred through the workflow of human supplement until the new action cell is formed. Simultaneously, the sizes of resource cell, recruitment cell, and training cell all grow in order to satisfy the growing demand of actions.

\section{Organizational Performance Evaluations}

In order to analyze the organizational dynamics, the indicators for evaluating performance are constructed based on the structural model described in Section 3.
As mentioned in [34], we evaluate the performance using cost and benefit. The cost consists of $\operatorname{Cost}_{\mathrm{ReP}}$, Cost ${ }_{\text {Training, }}$, Cost $_{\text {Recruit, }}$ and Cost Resource. These costs can be recorded during the simulation, and the total cost Cost total $_{\text {can be }}$ calculated as

$$
\begin{aligned}
\text { Cost }_{\text {total }}= & \text { Cost }_{\text {ReP }}+\text { Cost }_{\text {Training }}+\text { Cost }_{\text {Recruit }} \\
& + \text { Cost }_{\text {Resource }}
\end{aligned}
$$

Organizational Size. The most intuitional evaluation of the development of terrorist network is the organizational size, that is, the total number of agents in the terrorist organization, and it can be calculated as follows:

$$
\begin{aligned}
\text { Size }_{G} & =|G| \\
& =\left|G_{\mathrm{RC}}\right|+\left|G_{\mathrm{Co}}\right|+\left|G_{\mathrm{TC}}\right|+\left|G_{\mathrm{Re}}\right|+\sum_{i}\left|G_{\mathrm{AC}}^{i}\right| .
\end{aligned}
$$

Action Cells. The number of action cells measures the growth of terrorist organization from the operational aspect. This can be measured through the value of $n_{\mathrm{ac}}$.

Organizational Benefits. The goal of terrorist organization is to perform attacks or take similar activities to reach political purpose. It is intuitional to use the number of completed tasks as the organizational benefits. The task set $\Phi$ contains all the 


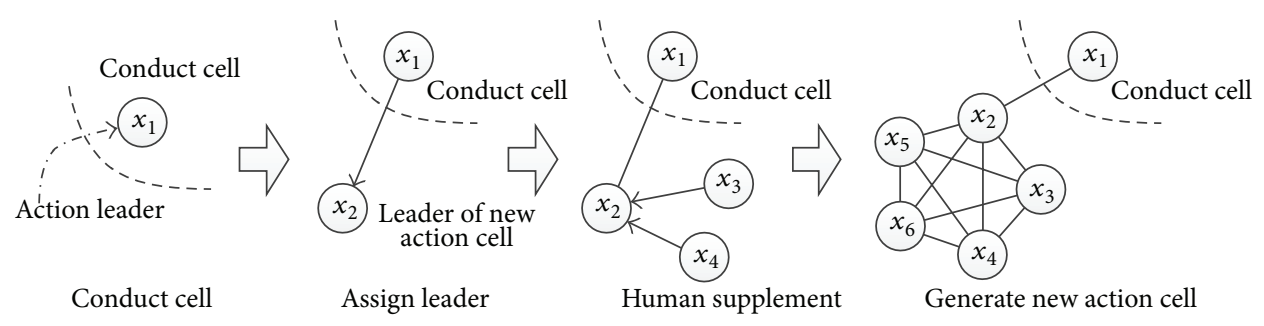

FIGURE 7: The growth mechanism of terrorist network.

tasks that have been performed. The benefit can be obtained using

$$
\text { Benefit }=|\Phi|=k
$$

Cost-Benefits Ratio. This is to evaluate the cost-benefit of the activity of performing tasks. As the terrorist organizational activity is task driven, we here only consider the requirement passing behavior, which measures the efficiency of how the terrorist is organized. The cost-benefit is measured by the rate of cost and benefit, which is denoted as $\mathrm{CB}$, so the cost-benefit of requirement passing $\mathrm{CB}_{\mathrm{ReP}}$ is calculated as

$$
\mathrm{CB}_{\mathrm{ReP}}=\frac{\text { Cost }_{\text {ReP }}}{\text { Benefit }} .
$$

The other cost-benefits $\mathrm{CB}_{\text {Training }}, \mathrm{CB}_{\text {Recruit }}$, and $\mathrm{CB}_{\text {Resource }}$ can also be calculated as (5).

\section{Experimental Results and Discussions}

In order to quantify the organizational dynamics, we performed the experiments in a simulation environment and discussed the performance and the influence factors based on the results. Potential strategies for counterterrorism are discussed with the results of sensitivity analysis.

6.1. Experimental Setup. The initial organizational structure of terrorist network was generated as shown in Figure 2, as well as the roles of the individuals. We tested the organizational dynamics model in an open environment, where the number of actions at each simulation step was not limited. In order to carry out a comparative analysis, we also used a limited environment with a parameter to represent the limited cost $\sigma_{\text {Cost }}$, which was the number of actions that can be taken at each step in the network:

(1) The initial terrorist network included a conduct cell, three action cells, a resource cell, a recruit cell, and a training cell. The simulation step was 1000 .

(2) At each step, cell leaders checked the situation of the cells and took actions based on the action set and workflows (e.g., action cell performs the task if all the requirements are finished). After that, the message lists of the agents who related to the actions were updated.
(3) The structure of terrorist network was changed based on the results of the cell actions (lose members, links, etc.).

(4) At each step, the agents updated their message lists according to the interactive mechanism described above, including message lists of themselves and the message lists of the interactive objects. The number of actions which can be taken by an agent at one step is denoted as $\sigma_{\text {Behavior }}$.

(5) At each step, the organization checks the number of completed tasks. If it reached a threshold $\sigma_{\text {Task }}$, a new action cell would be generated by the member in the conduct cell. This means that a new action cell is generated at the time every $\sigma_{\text {Task }}$ tasks are performed.

(6) In the limited environments, if the amount of actions at each step reached a threshold $\sigma_{\text {Cost }}$, the actions of the rest of agents at current step were stopped until the next step.

For clarity, the values of parameters that are used in this experiment and their explanations are listed in Table 3.

\subsection{Organizational Dynamics}

6.2.1. Organizational Performance. Figure 8 shows the simulation results of organizational performance. First, the increase of costs (Figure 8(a)) and tasks (Figure 8(b)) tends to accelerate over time, and this is because of the growth of terrorist organization. This is consistent with the results of empirical studies that the violent events tend to accelerate with increasing size and experience [33]. There is a similar linear relationship between the cost and completed tasks. Although the cost during the processes of recruiting and resource acquirement depends on the probabilities, which are influenced by randomness, the results show statistical linear relationship. It is easy to understand because the organizational behaviors are driven by task. Second, the values of Cost $t_{\text {Recruit }}$ and Cost Resource $_{\text {are much higher than }}$ Cost $_{\text {Training, }}$, and this is caused by the probabilistic behaviors of recruitment and resource acquirement. The sum of Cost $_{\text {Training }}$, Cost $t_{\text {Recruit }}$, and Cost $t_{\text {Resource }}$ is much higher than that of Cost $t_{\mathrm{ReP}}$, and this is consistent with the results of empirical studies that the preparation of a task is much more expensive than performing a task because multiple actions are required to launch an attack. Third, Figure 8(a) shows the differences caused by the task workflows. Cost ${ }_{\text {Recruit }}$ and Cost $_{\text {Resource }}$ are influenced by the probabilities. The action 
TABle 3: Parameters setting.

\begin{tabular}{|c|c|c|}
\hline Parameters & Values & Explanations \\
\hline$\overline{n_{\mathrm{ac}}}$ & 3 & The initial number of action cells \\
\hline$\left|N_{\mathrm{AC}}\right|$ & 5 & The number of agents in an action cell \\
\hline$\left|N_{\mathrm{Co}}\right|$ & 4 & The number of agents in a conduct cell \\
\hline$\left|N_{\mathrm{RC}}\right|$ & 6 & $\begin{array}{l}\text { The initial number of agents in a resource } \\
\text { cell }\end{array}$ \\
\hline$\left|N_{\mathrm{TC}}\right|$ & 6 & $\begin{array}{l}\text { The initial number of agents in a training } \\
\text { cell }\end{array}$ \\
\hline$\left|N_{\mathrm{Re}}\right|$ & 6 & $\begin{array}{l}\text { The initial number of agents in a recruit } \\
\text { cell }\end{array}$ \\
\hline Step & 1000 & The number of simulation steps \\
\hline$P_{\text {Recruit }}$ & 0.1 & The probability of recruitment \\
\hline$P_{\text {Resource }}$ & 0.1 & The probability of resource acquirement \\
\hline$P_{\text {arrest }}$ & 0.1 & The probability of arrest \\
\hline$P_{\text {reconnect }}$ & 0.1 & The probability of reconnection \\
\hline$\sigma_{\text {Behavior }}$ & 3 & $\begin{array}{l}\text { The number of behaviors that can be } \\
\text { taken by each agent in one step }\end{array}$ \\
\hline$\sigma_{\text {Training }}$ & 20 & The time of training a member \\
\hline$\sigma_{\text {Task }}$ & 50 & $\begin{array}{l}\text { The threshold of tasks completed for } \\
\text { building new action cell }\end{array}$ \\
\hline$\sigma_{\text {Cost }}$ & 30 & $\begin{array}{l}\text { The threshold of cost limited at each step } \\
\text { (in limited environment) }\end{array}$ \\
\hline$\varphi($ agent $)$ & 5 & $\begin{array}{l}\text { The number of humans required to } \\
\text { perform a task }\end{array}$ \\
\hline$\varphi($ agent $)$ & 1 & $\begin{array}{l}\text { The number of resources required to } \\
\text { perform a task }\end{array}$ \\
\hline
\end{tabular}

may need to be taken many times before its success, and it causes higher cost. On the other hand, with low arrest probability, the number of recruit requirements is smaller than the number of resource requirements; thus, Cost $_{\text {Recruit }}$ is lower than Cost $_{\text {Resource }}$. Fourth, because of the growth mechanism and human consumption, the number of agents shows a trend of fluctuating growth (Figure 8(c)). During this process, the mechanisms of network growth and recovery are the main factors for terrorist network to grow. Compared with the agent number, the cell number is more stable (Figure 8(d)).

Figure 8 has shown the general performance of the terrorist organization in a given environment. For further analysis of the organizational dynamics, the total cost Cost $_{\text {total }}$ at each step is given in Figure 9. Despite overall growth of performance, the number of actions at each step is fluctuating. The curve shows that the activities of terrorists are very irregular, even in the case of regular working processes. Besides, the organizational activity can be very elastic, and this indicates that the task driven mechanism makes the terrorists do not need to act all the time, which is an important requirement of security for terrorist organization. The fluctuating curves of activity at each step and its corresponding organizational size show that the general SNA method may be ineffective when analyzing the dynamics of terrorist network.

Figure 10 shows the results of organizational cost-benefit ratio. It is interesting that the four curves are fluctuating and increasing and finally reach relative stable values. Particularly, $\mathrm{CB}_{\mathrm{ReP}}$ shows the same trend with the other costbenefit ratios. At the beginning of the simulation, because of the low requirement and initial state of the organization (resource, human, etc.), all the costs are relatively low. With the increase of requirement, the costs are increasing and finally reach a relatively stable state. This trend implies that, in an environment of persistence activity, the cost of performing a task is stable although the structure of the organization changes (building new links). This is the result of cooperation by the terrorists according to the organizational process. As a system, the performance of the organization is limited by the overall input, but the efficiency is determined by the interaction between the individuals and corresponding behaviors (building new link, efficient requirement passing).

6.2.2. Organizational Performance in a Limited Environment. Figures 11(a) and 11(b) show that the cost limitation at each step can slow down the speed of task growth. The influence is not obvious at the beginning. With the growth of terrorist network, the number of actions to be taken at each step is increasing (Figure 11(b)). The limitation reduces the number of actions, which slows down the process of workflows to reduce the number of completed tasks.

This result means that the limitation of the organizational activities can reduce the terror events by limiting the efficiency of organization, which leads to the drastic fluctuating of the agent number, as in Figure 11(b), compared with Figure 8(c). The reason of this result is that the assumption speed is higher than the recovery speed. As the action cell cannot recover timely, the period of performing a task is getting longer, which leads to the overall decrease of the completed task.

Towards the cost-benefit ratio, Figure 11(d) shows similar trend as in Figure 10. This means that the limitation of organization activity can only slow down the organization process but has no effect on the task assumption. This is because the limitation operation has an effect on the organizational structure, which means that the external environment of the organization determines the organizational production, and the internal structure and mechanism determine the organizational efficiency.

6.3. Sensitivity Analysis and Potential Strategies. Different values of the parameters change the operational environments of terrorist network. The organizational dynamics can be tested in various circumstances and the influence factors can be analyzed for strategy construction. The four probabilities parameters are built to model the interaction between the organization and the environment. The three threshold parameters are built to control the internal organizational processes. We here focus on the number of completed tasks and the cost-benefit ratio $\left(\mathrm{CB}_{\mathrm{ReP}}\right)$, as well as how the changes of parameters affect the performance. This part presents the operational validation of the simulation experiments, including the sensitivity analysis and randomness effects. The potential strategies are also discussed. 


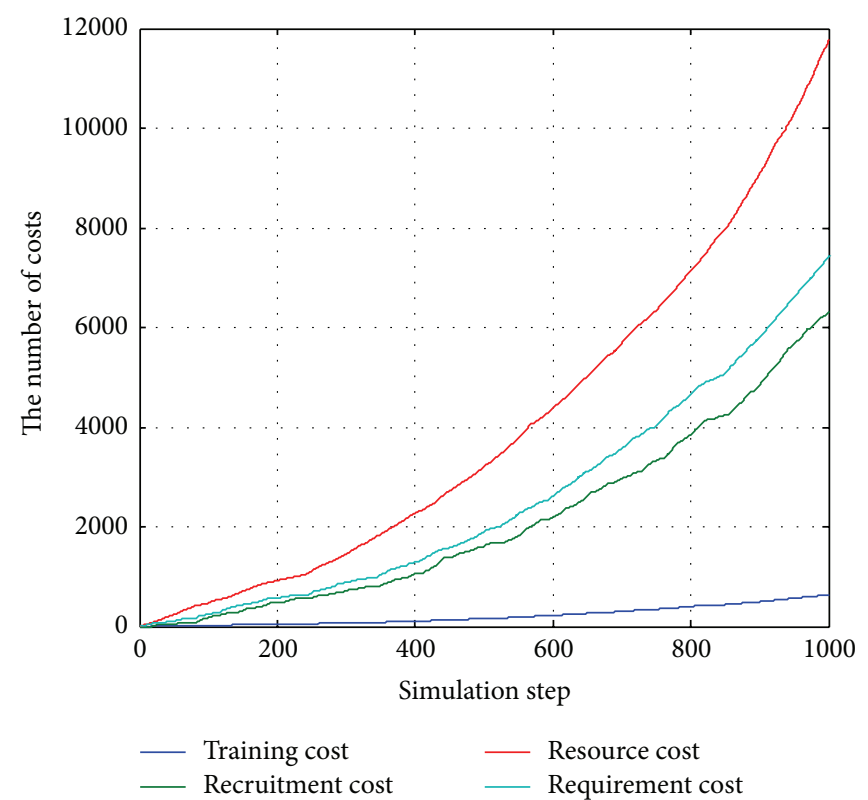

(a)

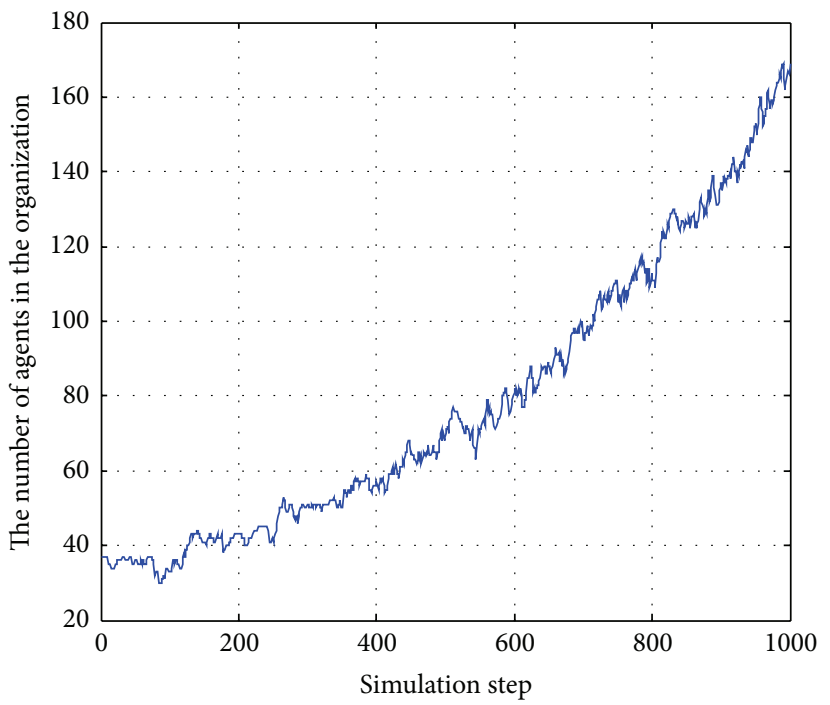

(c)

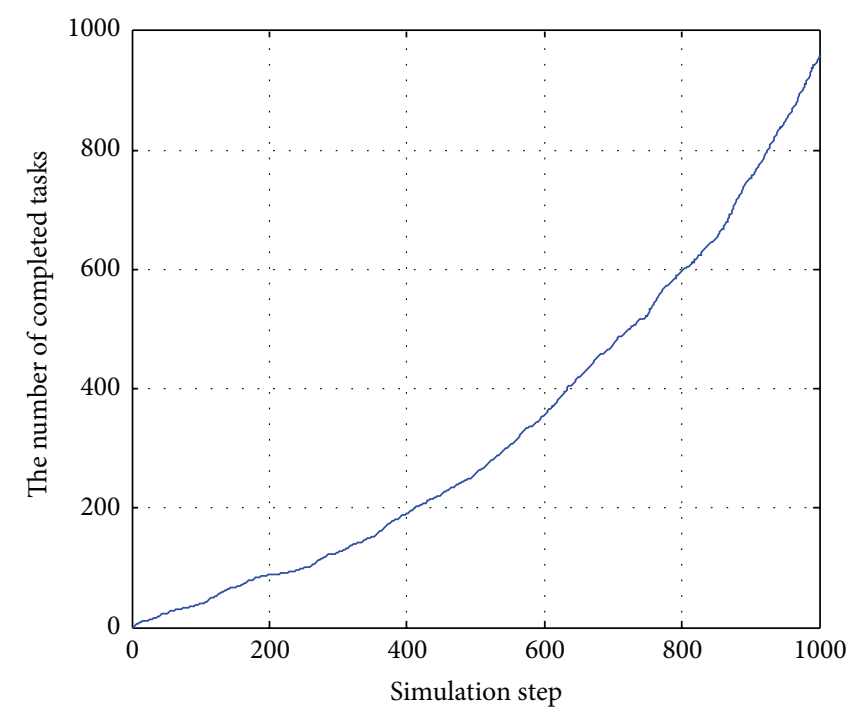

(b)

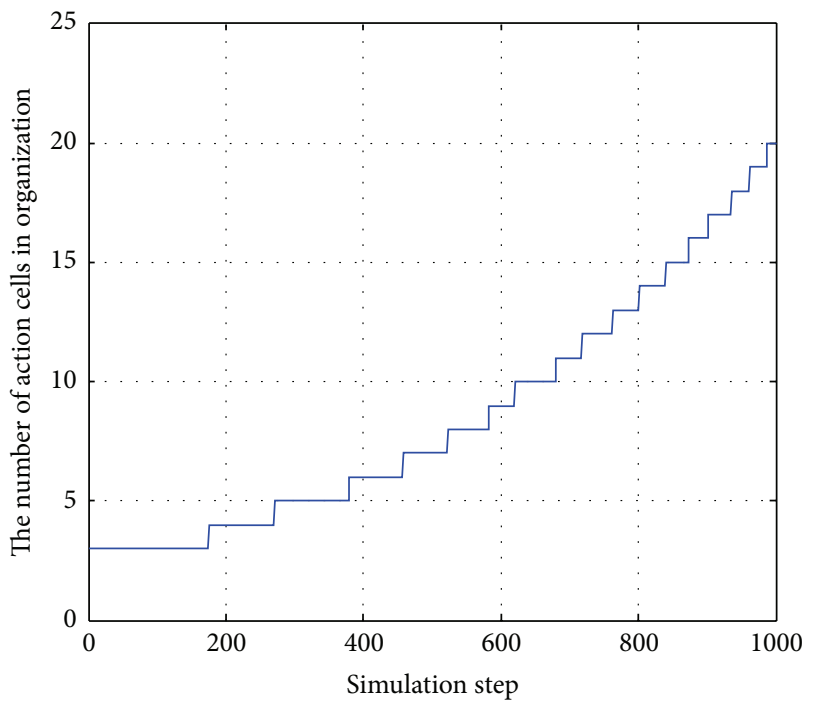

(d)

FIGURE 8: Simulation results of organizational performance, (a) the cost during the simulation period, (b) the number of completed tasks, (c) the number of agents in the organization, (d) and the number of action cells in the organization.

6.3.1. Parameters Sensitivity and Potential Strategies. Figure 12 shows the experimental results of performance with different probabilities of parameters. For each configuration, the experiment is repeated 10 times and the results at simulation step 1000 are recorded.

The results in Figures 12(a), 12(b), 12(g), and 12(h) show no apparent difference on the two evaluations, which means that the two parameters do not significantly affect the performance. For a growing organization, the efficiencies of recruitment and reconnection do not significantly affect the number of completed tasks. This result suggests that, with a low probability of arrest (0.1), the strategy of intervening in organizational recruitment would not significantly reduce the activities of terrorists. For the resource acquirement, as shown in Figure 12(c), there is no significant influence unless the probability is set to a very low value $(0.1)$. This means that unless the strategy of resource controlling can reduce the probability of resource acquirement to a very low value, the organizational performance will not be significantly influenced. The results in Figures 12(e) and 12(f) indicate that the difference of arrest probability considerably affects the performance. When the other conditions are invariable, improving the efficiency of arrest criminals may be the most effective way to reduce the performance of terrorist network. Although it does not help to prevent the events that have happened, it significantly reduces the growth and violent 


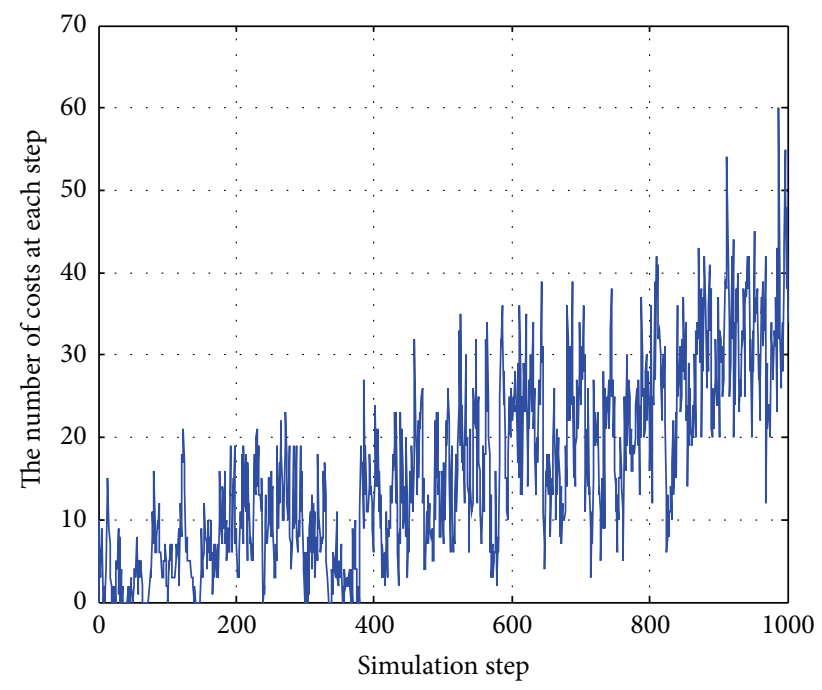

FIgURE 9: The number of costs at each step.

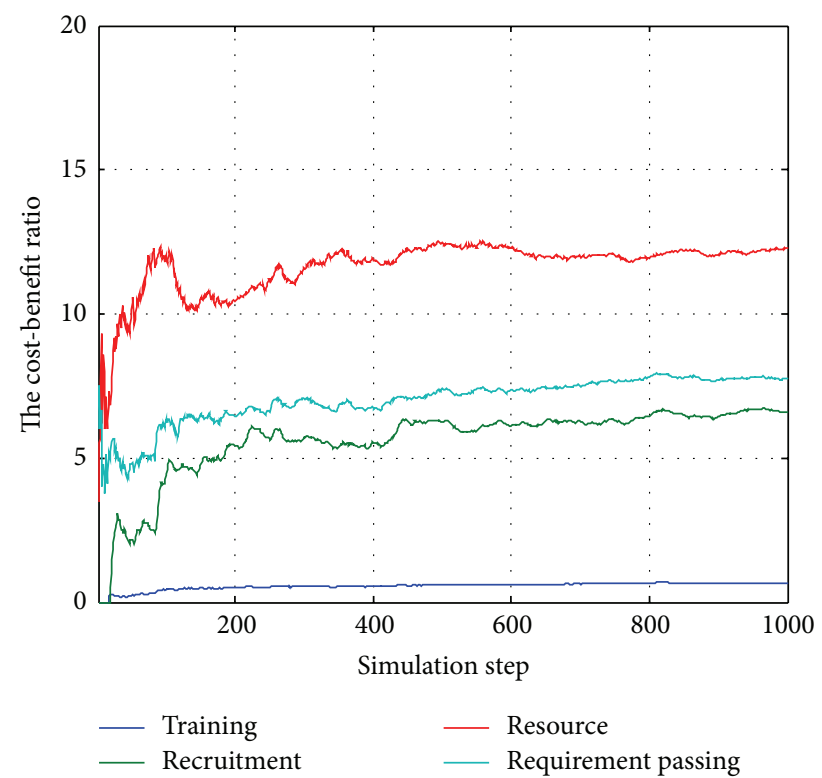

Figure 10: Simulation results of organizational cost-benefit ratio.

events in a long time, even more effective than the strategies of reducing the abilities of terrorists to recruit or to acquire resource. Another significant result is that the cost-benefit ratio is increasing, which means the organization would be much harder to perform a task in a high arrest probability.

Besides probability parameters, the influences of thresholds parameters are also analyzed with results shown in Figure 13. It is interesting that the values of the three parameters all have significant effects on the number of completed tasks. A terrorist organization grows faster if it performs more tasks with high efficiency. Another notable observation is that the cost-benefit ratio of $\sigma_{\text {behavior }}$ and $\sigma_{\text {Training }}$ scarcely changed. This result means that even though the completed tasks are changed, the ability of the terrorist organization to perform a task is still unchanged (Figures 13(b) and
TABLE 4: Statistical significance of different probabilities.

\begin{tabular}{lcccc}
\hline Probability & $P_{\text {Recruit }}$ & $P_{\text {Resource }}$ & $P_{\text {arrest }}$ & $P_{\text {reconnect }}$ \\
\hline $0.1-0.2$ & 0.916 & $0.000^{*}$ & $0.000^{* *}$ & $0.009^{*}$ \\
$0.2-0.3$ & 0.495 & $0.097^{*}$ & $0.000^{* *}$ & $0.148^{*}$ \\
$0.3-0.4$ & 0.710 & $0.016^{*}$ & $0.000^{* *}$ & $0.728^{*}$ \\
$0.4-0.5$ & 0.644 & $0.135^{*}$ & $0.000^{* *}$ & $0.575^{*}$ \\
$0.5-0.6$ & 0.808 & $0.926^{*}$ & $0.000^{* *}$ & $0.100^{*}$ \\
$0.6-0.7$ & 0.444 & $0.341^{*}$ & $0.000^{* *}$ & $0.358^{*}$ \\
$0.7-0.8$ & 0.138 & $0.196^{*}$ & $0.000^{* *}$ & $0.216^{*}$ \\
$0.8-0.9$ & 0.050 & $0.971^{*}$ & $0.000^{* *}$ & $0.650^{*}$ \\
$0.9-1.0$ & 0.151 & $0.485^{*}$ & $0.001^{* *}$ & $0.765^{*}$ \\
\hline${ }^{*} P<0.01{ }^{*} P<0.001$ & & &
\end{tabular}

13(d)). In Figures 13(e) and 13(f), not only does the number of completed tasks decrease, but also the cost-benefit ratio decreases. This indicates that the task threshold not only can slow down the growth of the organization, but also can improve the efficiency of group.

For intervention strategies, it is easy to find that the strategies targeting at these parameters are all effective. Strengthening the security environment can reduce the active frequency of terrorists, which means that the behaviors of agent in a step $\left(\sigma_{\text {Behavior }}\right)$ will be reduced. Intervention on the interaction of terrorist will prolong the time of training an agent $\left(\sigma_{\text {Training }}\right)$. Reducing the social influence of terrorist attacks would raise the threshold of building new action cell $\left(\sigma_{\text {Task }}\right)$. From the perspective of organizational dynamics, these strategies may be more effective than finding potential terrorists to reduce the recruitment of terrorist organization (as shown in Figure 12(a)).

For further investigation of the task performance, the experiments with different arrest probability are performed and the results are shown in Figure 14. With the increase of arrest probability, $\mathrm{CB}_{\mathrm{Tra}}, \mathrm{CB}_{\mathrm{rec}}$, and $\mathrm{CB}_{\mathrm{ReP}}$ are increasing. This is because the probability is related to the organizational structure and task performance. Another result is that Cost $_{\text {ReP }}$ becomes higher than Cost $_{\text {Rec }}$; this means that when the arrest probability reaches a level (in this case, 0.3 ), the highest assumption of the organization would be the requirement passing, which means that the main cost for performing task is the individual interaction.

6.3.2. Statistical Tests of Randomness Effects. In order to examine the extent to which the randomness affects the simulation results, the experiment was tested following a procedure of factorial analysis. This section presents the statistical significance of the experiments performed in Section 6.3.1, and the results are shown in Tables 4 and 5 $(P<0.05, *$ for $P<0.01$, and $* *$ for $P<0.001)$. In this analysis, the value used for test is the number of completed tasks in the simulation process. The consistency between this section and previous results proved that the difference of the experiments is caused by the model, not the randomness, and the previous analysis is meaningful.

Table 4 shows the results of statistical significance with different probabilities. The test is carried out between two 


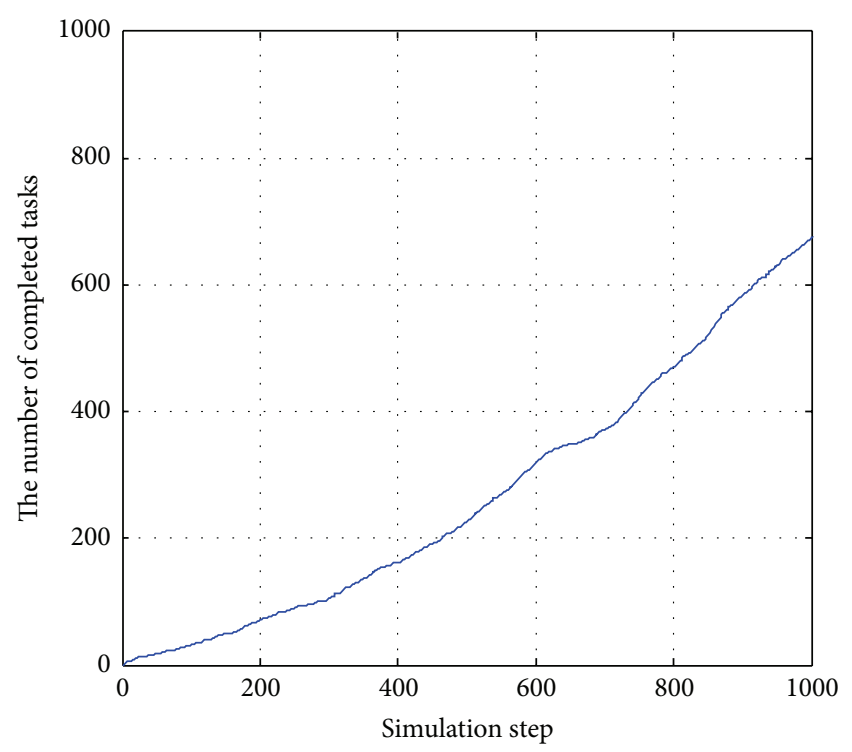

(a)

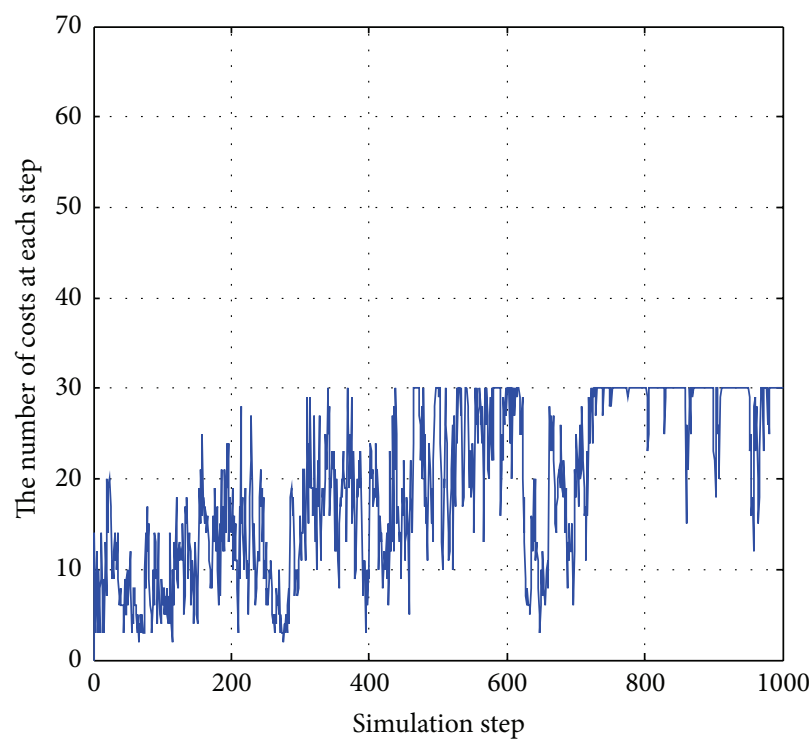

(c)

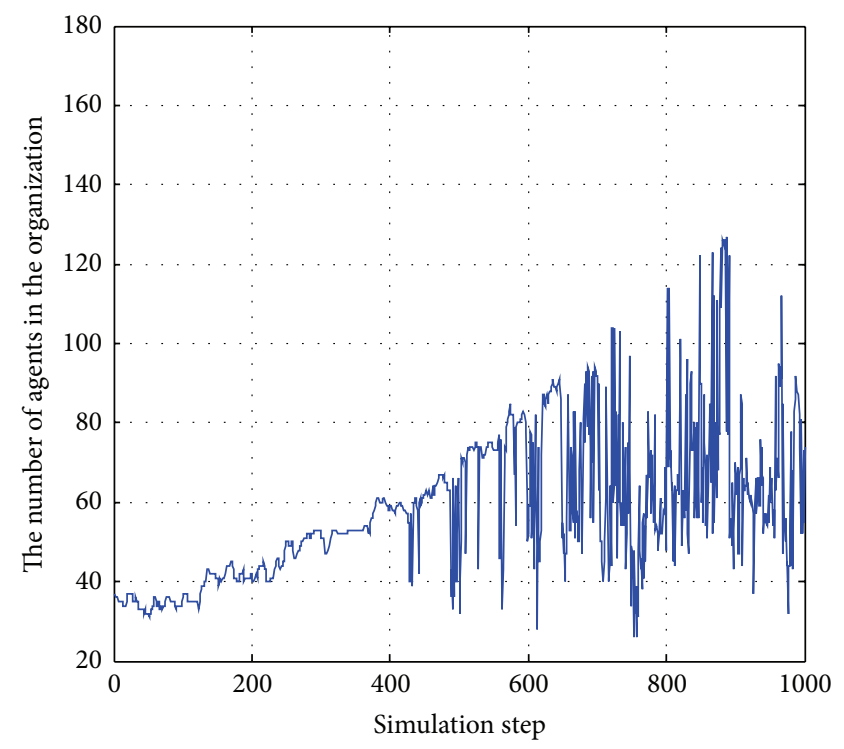

(b)

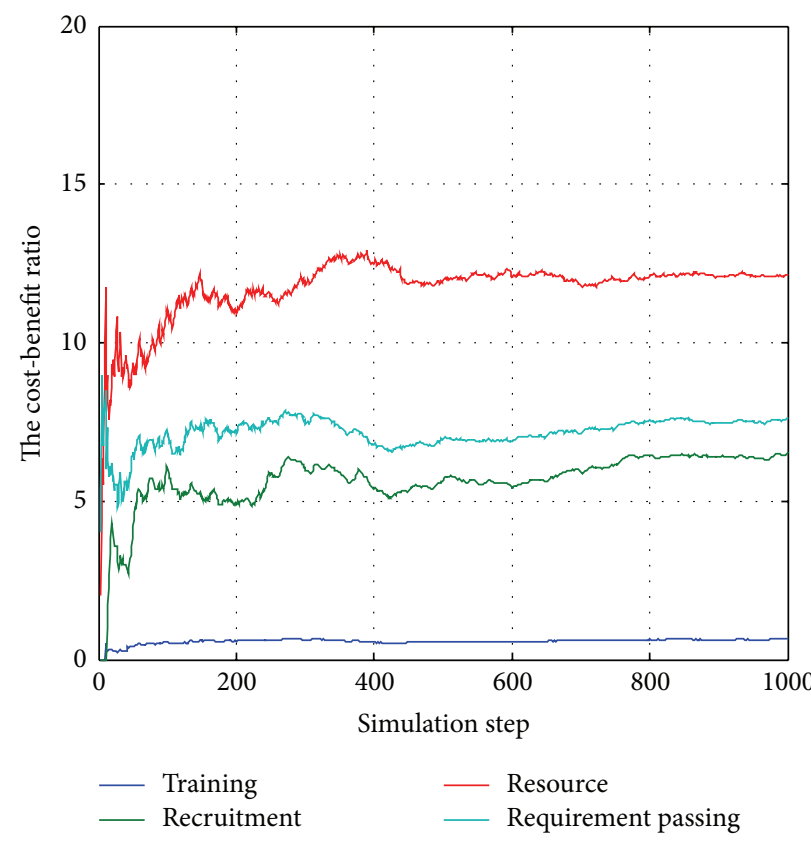

(d)

FIGURE 11: The organizational performance in a limited environment.

TABLE 5: Statistical significance of different thresholds.

\begin{tabular}{lccc}
\hline Number & $\sigma_{\text {Behavior }}$ & $\sigma_{\text {Training }}$ & $\sigma_{\text {Task }}$ \\
\hline 1 & $0.000^{* *}(1,2)$ & $0.063^{*}(10,20)$ & $0.000^{* *}(30,40)$ \\
2 & $0.000^{* *}(2,3)$ & $0.091^{*}(20,30)$ & $0.000^{* *}(40,50)$ \\
3 & $0.000^{* *}(3,4)$ & $0.000^{* *}(30,40)$ & $0.000^{* *}(50,60)$ \\
4 & $0.000^{* *}(4,5)$ & $0.000^{* *}(40,50)$ & $0.000^{* *}(60,70)$ \\
\hline${ }^{*} P<0.01 ;{ }^{*} P<0.001$. & &
\end{tabular}

adjacent probabilities. For example, in the probability row 0.1-0.2, the value in $P_{\text {Recruit }}$ column means that it is the statistical significance result between the group $P_{\text {Recruit }}=$ 0.1 and the group $P_{\text {Recruit }}=0.2$. The values in the table show the same conclusions discussed in Figure 12. The change of arrest probability significantly affects the organizational performance. For the probabilities of resource acquirement and reconnection, only in the case of low probabilities (0.10.2 ), the changes of probabilities can significantly affect the results.

Table 5 shows the test results with different values of thresholds. The results are calculated between every two adjacent values of the thresholds. Since, in Section 6.3.1, each parameter is tested with 5 values, the statistical significance 


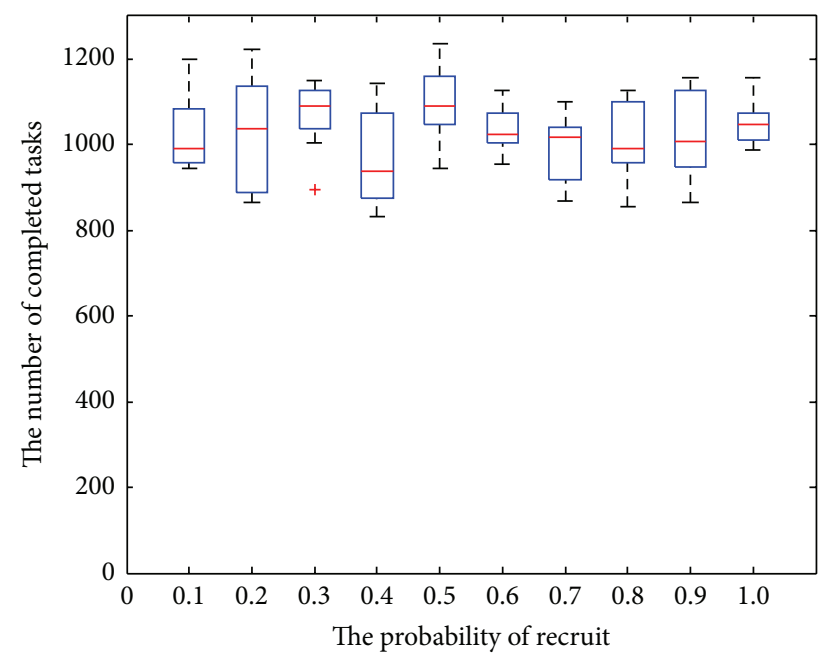

(a)

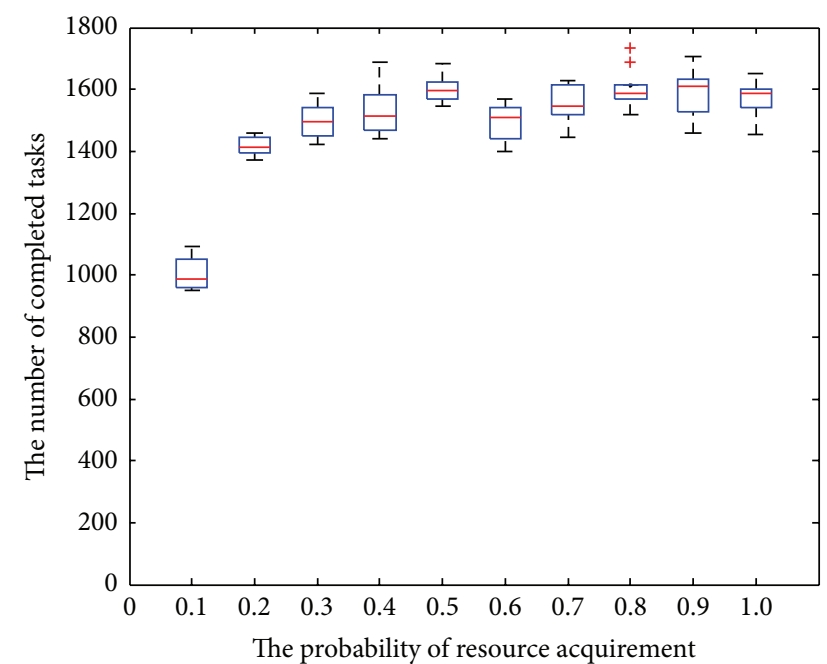

(c)

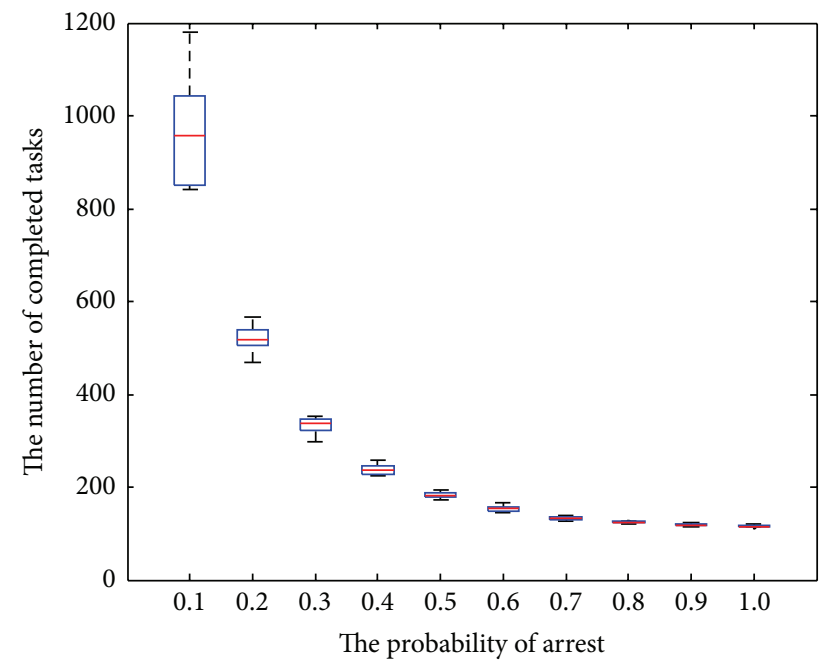

(e)

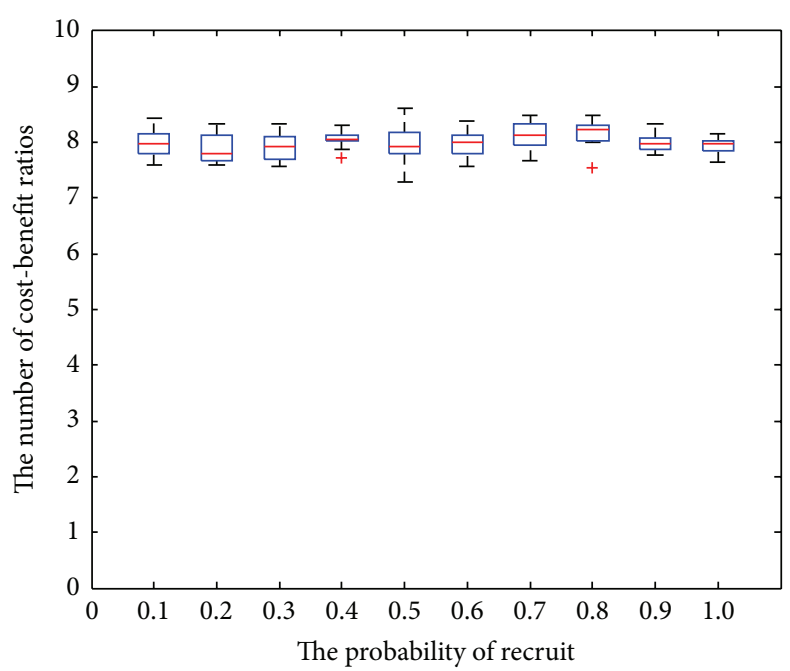

(b)

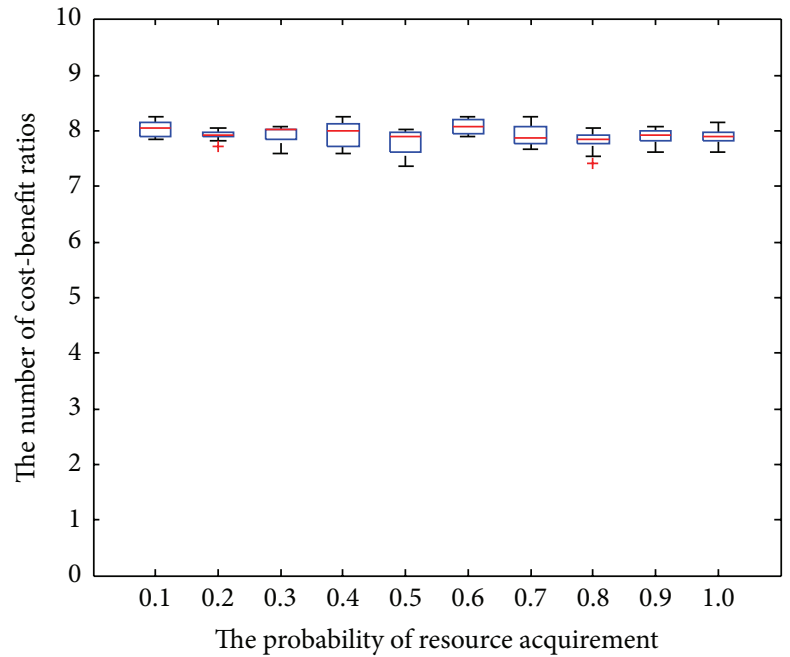

(d)

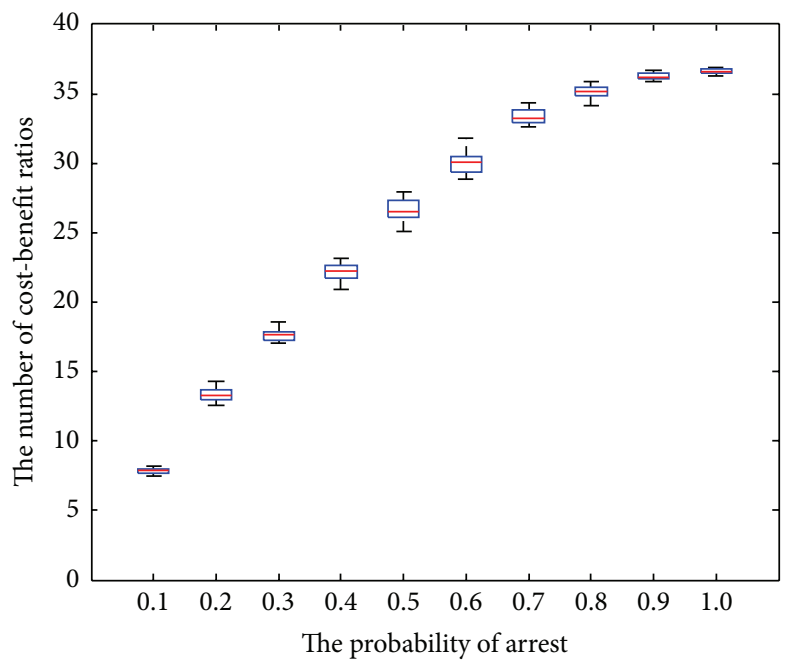

(f)

FIGURE 12: Continued. 


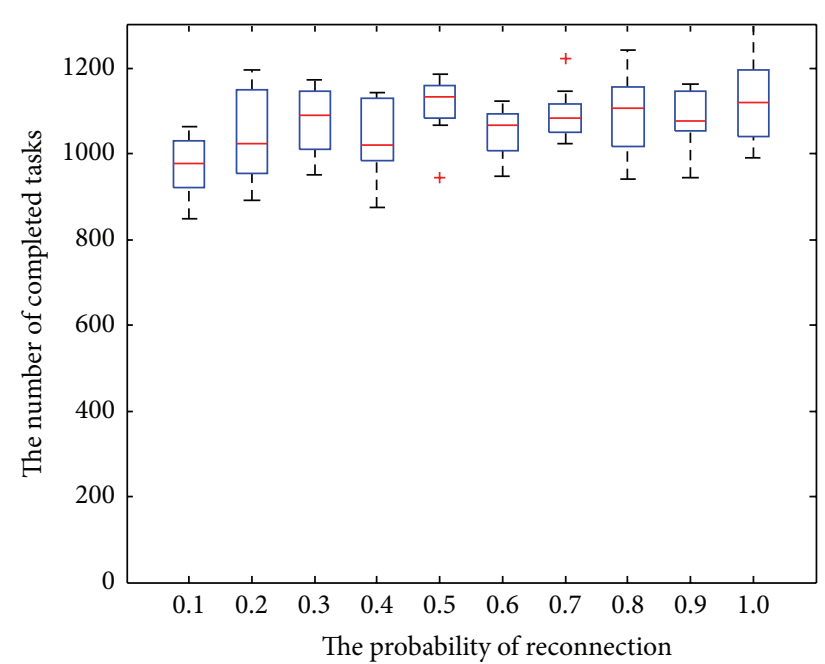

(g)

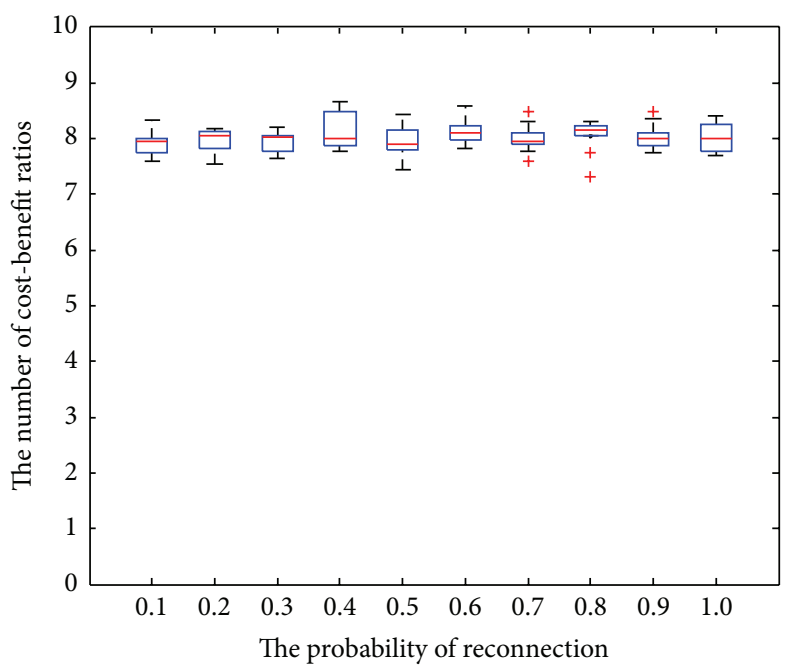

(h)

FIGURE 12: Simulation results of organizational performance with different (a)-(b) recruit probability, (c)-(d) resource probability, (e)-(f) arrest probability, and $(\mathrm{g})-(\mathrm{h})$ reconnection probability.

is carried out between two adjacent values. The values in parentheses are the two values of the threshold parameter. From the results, it is easy to find that they show consistent conclusions in Figure 13. Except when $\sigma_{\text {Training }}$ is low (10$20,20-30)$, the results of the other groups are all statistically significant.

\section{Conclusion}

This paper studied the organizational dynamics of terrorist network by incorporating a hierarchical cellular network model and mechanisms of organizational processes. Modeling and simulating the dynamic adaptive behaviors of terrorists enable us to quantitatively investigate the emergent dynamics of organization and to find the influencing factors for constructing intervention strategies. Our main conclusions are summarized as follows:

(1) For a continuous active terrorist organization, the organizational performance is influenced by both the interactional environment and the organizational mechanism. The efficiency of the organization will be fluctuating and finally reach a relative stable state, and the state is determined by both the external input and internal structure and mechanism. This shows the characteristics of terrorist organization as a complex system.

(2) Even in a regular organizational process, the activity of the terrorist is irregular (as Figure 9 shows). The size of the organization shows a trend of fluctuating growth under the organizational mechanisms and consumption. The recovery mechanism enables the organization to survive and grow in case of losing members.
(3) In a limited operational environment, the organization shows more uncertainty in the organization size and growth (as in Figure 11(b)). This environment can only "slow down" the process of organizational development and the assumption for task is unchanged, and this is because the limited environment cannot change the organizational structure and process.

(4) For counterterrorism, the most effective strategy should be those which have effect on both the organizational structure and the organizational process. From this perspective, the strategy which can increase the arrest rate or reduce the frequency of building new action cell will be the most useful. The other strategy which has effect on the active frequency of the terrorist, the training time, and the resource acquirement can only reduce the launched events, not the efficiency of the organization.

In conclusion, this work gives a new insight into organizational dynamics of terrorist network by using ABM method. It can be used to test various simulation experiments to investigate organizational dynamics under different scenarios. Based on the simulation framework, different strategies can be examined for making counterterrorism policy. A future development of this research would be to apply this method to study the evolution of terrorist network under different intervention strategies.

\section{Conflict of Interests}

The authors declare that there is no conflict of interests regarding the publication of this paper. 


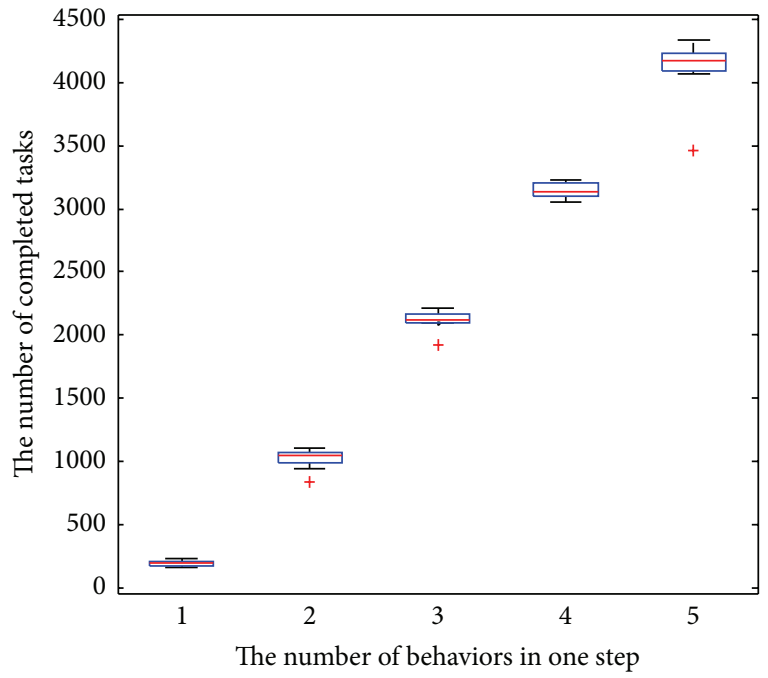

(a)

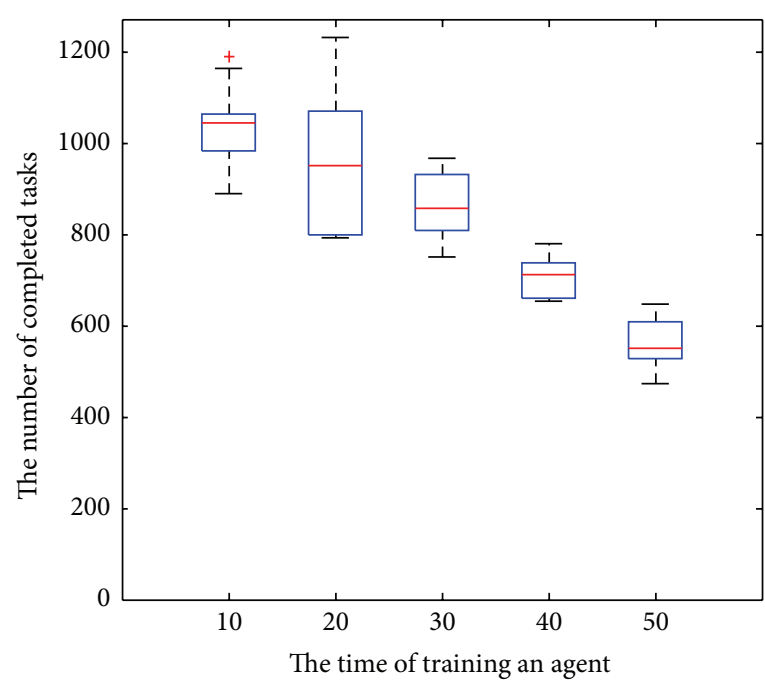

(c)

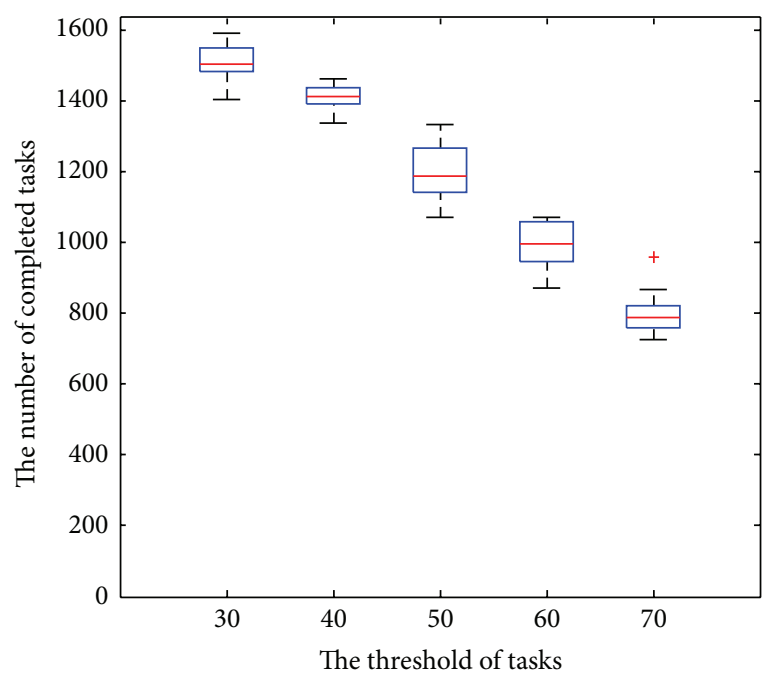

(e)

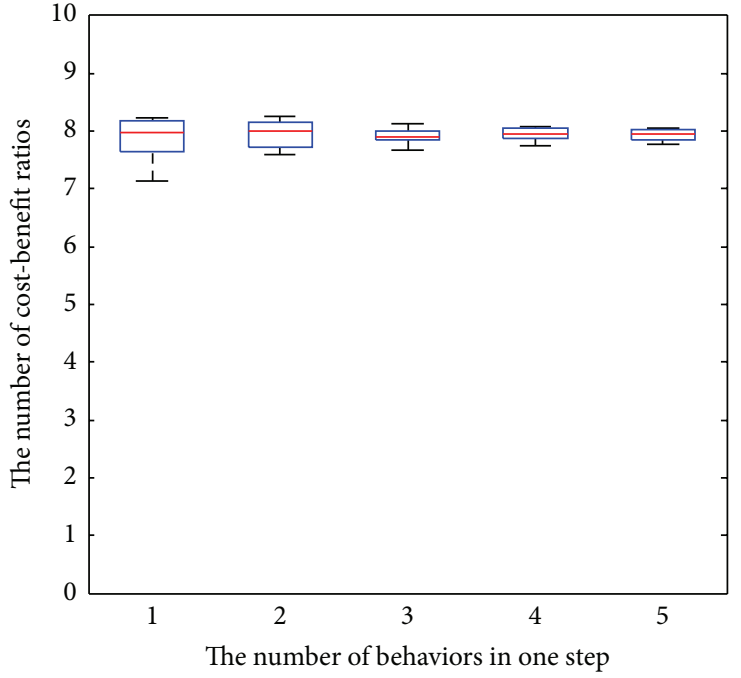

(b)

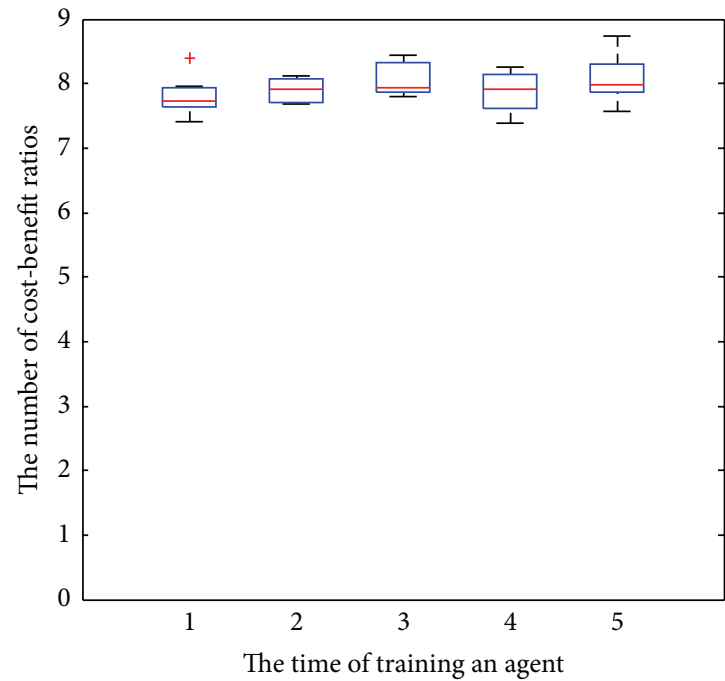

(d)

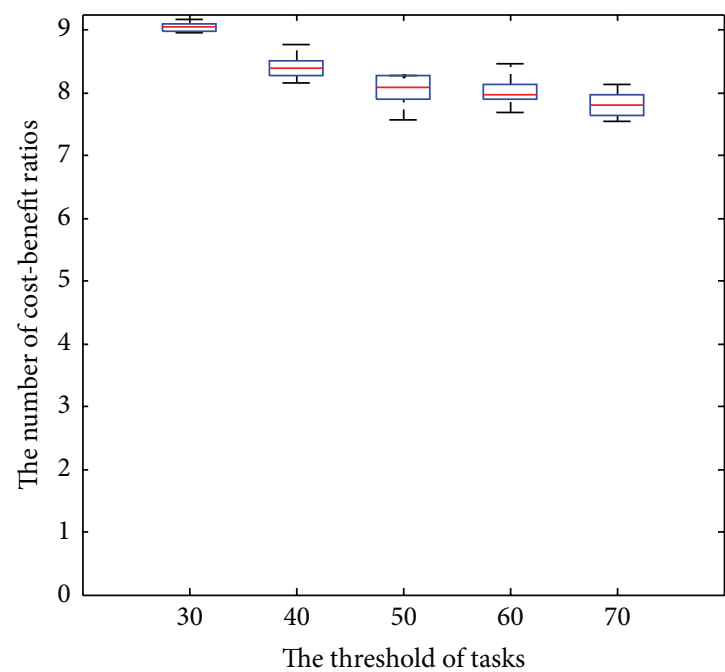

(f)

FIGURE 13: Simulation results of organizational performance with different (a)-(b) threshold of activities, (c)-(d) time of training, and (e)-(f) thresholds of tasks. 


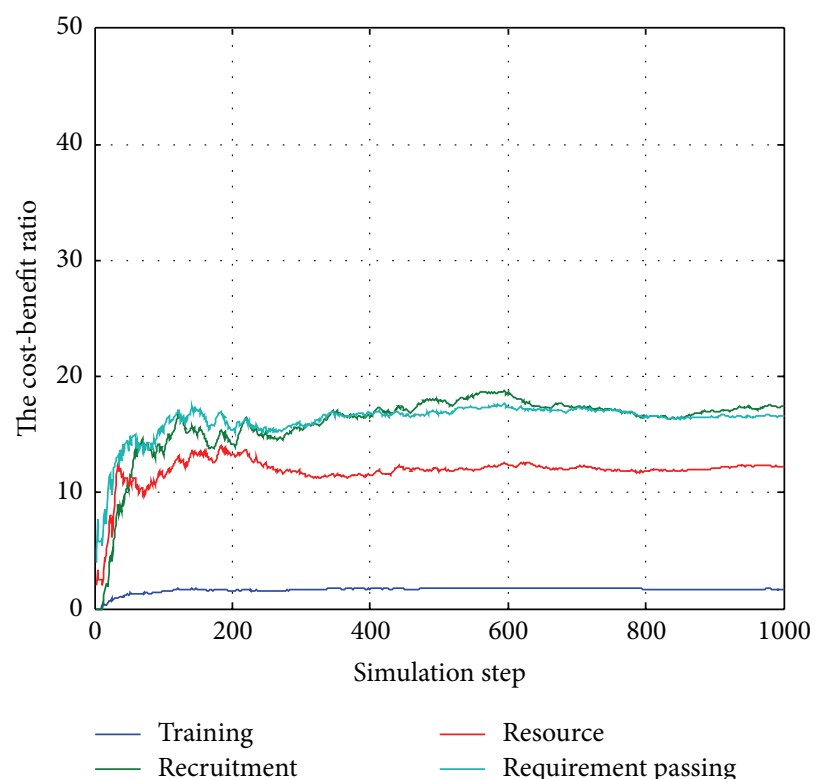

(a)

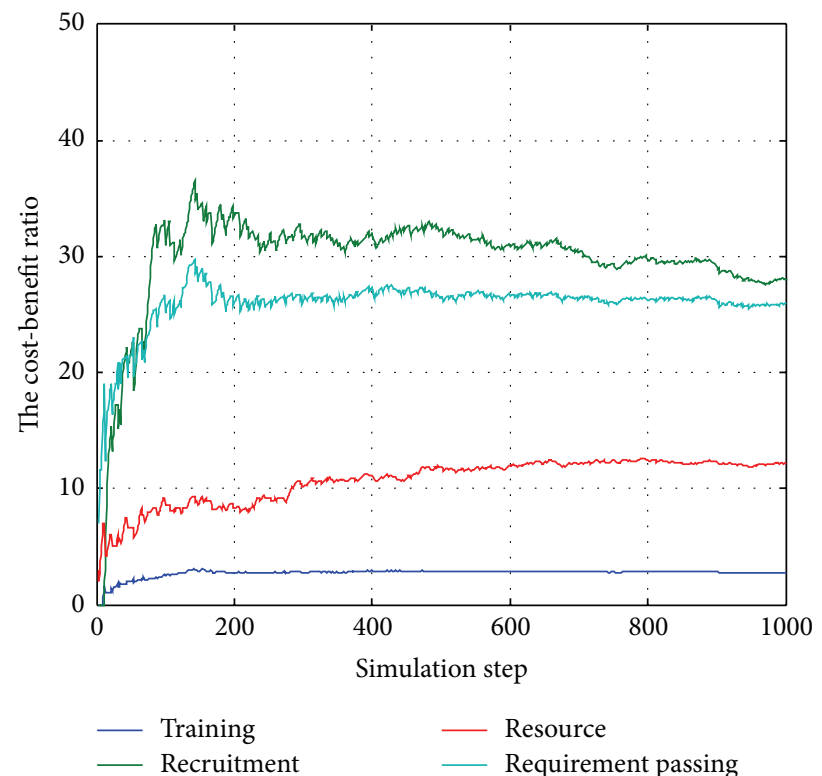

(b)

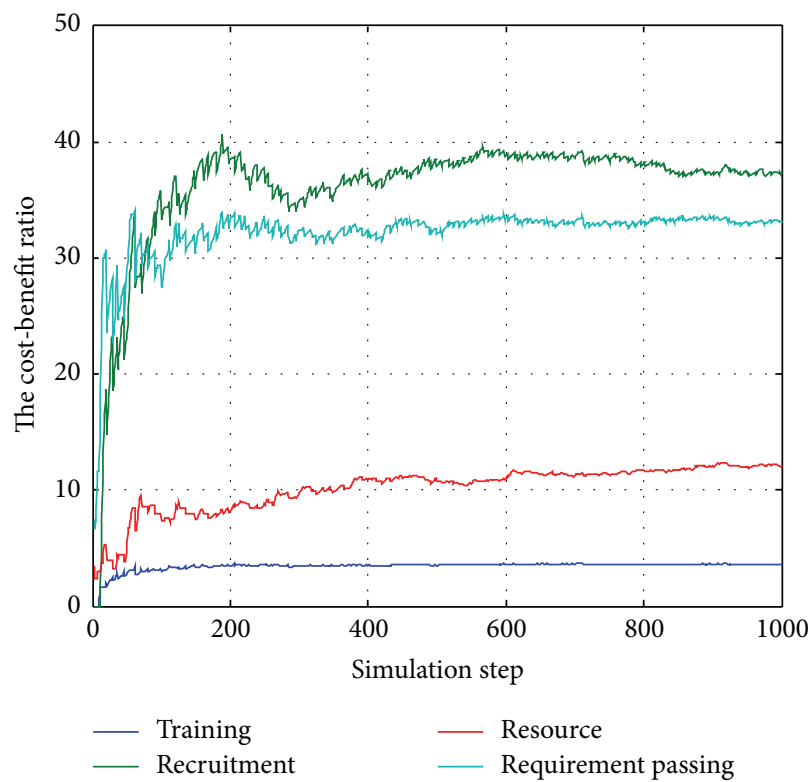

(c)

FIGURE 14: Simulation results of cost-benefit ratio under different arrest probability: (a) 0.3, (b) 0.5, and (c) 0.7.

\section{Acknowledgments}

This work is supported by the National Natural Science Foundation of China (Grant no. 71473263) and the Specialized Research Fund for the Doctoral Program of Higher Education of China (Grant no. 20134307110020).

\section{References}

[1] D. Conway, Modeling Network Evolution Using Graph Motifs, Computing Research Repository (CoRR), 2011.

[2] D. Garlaschelli, A. Capocci, and G. Caldarelli, "Self-organized network evolution coupled to extremal dynamics," Nature Physics, vol. 3, no. 11, pp. 813-817, 2007.
[3] T. A. B. Snijders, C. E. G. Steglich, and M. Schweinberger, "Modeling the co-evolution of networks and behavior," in Longitudinal Models in the Behavioral and Related Sciences, K. V. Montfort, J. Oud, and A. Satorra, Eds., pp. 41-71, Lawrence Erlbaum Associates, 2007.

[4] F. Bergenti, E. Franchi, and A. Poggi, "Agent-based interpretations of classic network models," Computational and Mathematical Organization Theory, vol. 19, no. 2, pp. 105-127, 2013.

[5] M. E. J. Newman, "The structure and function of complex networks," SIAM Review, vol. 45, no. 2, pp. 167-256, 2003.

[6] P. V. Fellman and R. Wright, "Modeling terrorist networks, complex systems at the mid-range," in Proceedings of the Complexity, Ethics and Creativity Conference, London, UK, 2003. 
[7] R. Lindelauf, P. Borm, and H. Hamers, "The influence of secrecy on the communication structure of covert networks," Social Networks, vol. 31, no. 2, pp. 126-137, 2009.

[8] M. Sageman, Understanding Terror Networks, University of Pennsylvania Press, Philadelphia, Pa, USA, 2004.

[9] S. P. Borgatti, "Identifying sets of key players in a social network," Computational \& Mathematical Organization Theory, vol. 12, no. 1, pp. 21-34, 2006.

[10] V. E. Krebs, "Mapping networks of terrorist cells," Connections, vol. 24 , no. 3, pp. 43-52, 2001.

[11] H. Chen, Intelligence and Security Informatics for International Security, Springer, New York, NY, USA, 2005.

[12] P. J. Phillips, “The life cycle of terrorist organizations," International Advances in Economic Research, vol. 17, no. 4, pp. 369-385, 2011.

[13] K. M. Carley, "Destabilization of covert networks," Computational and Mathematical Organization Theory, vol. 12, no. 1, pp. 51-66, 2006.

[14] K. M. Carley, "Dynamic network analysis," in Dynamic Social Network Modeling and Analysis: Workshop Summary and Papers, pp. 133-145, National Academies Press, Washington, DC, USA, 2003.

[15] A. Ilachinski, "Modelling insurgent and terrorist networks as self-organised complex adaptive systems," International Journal of Parallel, Emergent and Distributed Systems, vol. 27, no. 1, pp. 45-77, 2012.

[16] L. Yilmaz, "Validation and verification of social processes within agent-based computational organization models," Computational and Mathematical Organization Theory, vol. 12, no. 4, pp. 283-312, 2006.

[17] S. Bandini, S. Manzoni, and G. Vizzari, "Agent based modeling and simulation: an informatics perspective," Journal of Artificial Societies and Social Simulation, vol. 12, no. 4, article 4, 2009.

[18] T. A. Leweling and M. E. Nissen, "Defining and exploring the terrorism field: toward an intertheoretic, agent-based approach," Technological Forecasting and Social Change, vol. 74, no. 2, pp. 165-192, 2007.

[19] G. A. Backus and R. J. Glass, An Agent-Based Model Component to a Framework for the Analysis of Terrorist-Group Dynamics, Sandia National Laboratories, Livermore, Calif, USA, 2006.

[20] P. O. Neil, "Dynamic, covert network simulation," in Social Computing, Behavioral-Cultural Modeling and Prediction, pp. 239-247, Springer Verlag, Berlin, Germany, 2012.

[21] M. Tsvetovat and M. Latek, "Dynamics of agent organizations: application to modeling irregular warfare," in Multi-AgentBased Simulation IX, vol. 5269 of Lecture Notes in Computer Science, pp. 60-70, Springer, Berlin, Germany, 2009.

[22] I.-C. Moon and K. M. Carley, "Modeling and simulating terrorist networks in social and geospatial dimensions," IEEE Intelligent Systems, vol. 22, no. 5, pp. 40-49, 2007.

[23] A. Vespignani, "Modelling dynamical processes in complex socio-technical systems," Nature Physics, vol. 8, no. 1, pp. 32-39, 2012.

[24] P. A. C. Duijn, V. Kashirin, and P. M. A. Sloot, “The relative ineffectiveness of criminal network disruption," Scientific Reports, vol. 4, article 4238, 2014.

[25] S. Helfstein and D. Wright, "Covert or convenient? Evolution of terror attack networks," Journal of Conflict Resolution, vol. 55, no. 5, pp. 785-813, 2011.

[26] D. Jones, Understanding the Form, Function, and Logic of Clandestine Insurgent and Terrorist Networks: The First Step in
Effective Counternetwork Operations, Joint Special Operations University, 2012.

[27] M. Tsvetovat and K. M. Carley, Structural Knowledge and Success of Anti-Terrorist Activity: The Downside of Structural Equivalence, Center for Computational Analysis of Social and Organizational Systems (CASOS), 2005.

[28] G. A. Henke, How Terrorist Groups Survive: A Dynamic Network Analysis Approach to the Resilience of Terrorist Organizations, School of Advanced Military Studies, 2009.

[29] T. L. Frantz and K. M. Carley, A Formal Characterization of Cellular Networks, CMU-ISRI-05-109, Center for Computational Analysis of Social and Organizational Systems (CASOS), 2005.

[30] F. Ozgul, "Classification of terrorist networks and their key players," in Multidisciplinary Social Networks Research, L. S.L. Wang and J. J. June, Eds., vol. 473 of Communications in Computer and Information Science, pp. 145-157, Springer, Berlin, Germany, 2014.

[31] C. Leuprecht and K. Hall, "Why terror networks are dissimilar: how structure relates to function," in Networks and Network Analysis for Defence and Security, A. J. Masys, Ed., Lecture Notes in Social Networks, pp. 83-120, Springer International Publishing, Gewerbestrasse, Switzerland, 2014.

[32] R. M. Bakker, J. Raab, and H. B. Milward, "A preliminary theory of dark network resilience," Journal of Policy Analysis and Management, vol. 31, no. 1, pp. 33-62, 2012.

[33] A. Clauset and K. S. Gleditsch, "The developmental dynamics of terrorist organizations," PLoS ONE, vol. 7, no. 11, Article ID e48633, 2012.

[34] D. Ye, M. Zhang, and D. Sutanto, "Self-organization in an agent network: a mechanism and a potential application," Decision Support Systems, vol. 53, no. 3, pp. 406-417, 2012. 


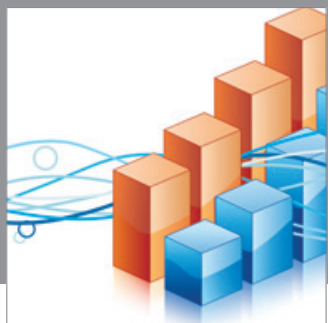

Advances in

Operations Research

mansans

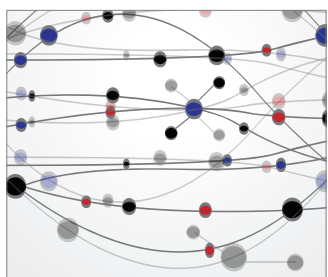

The Scientific World Journal
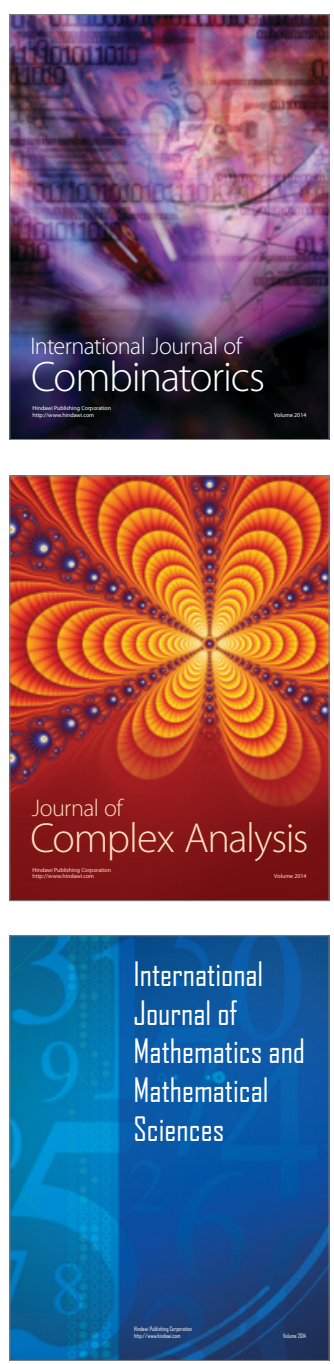
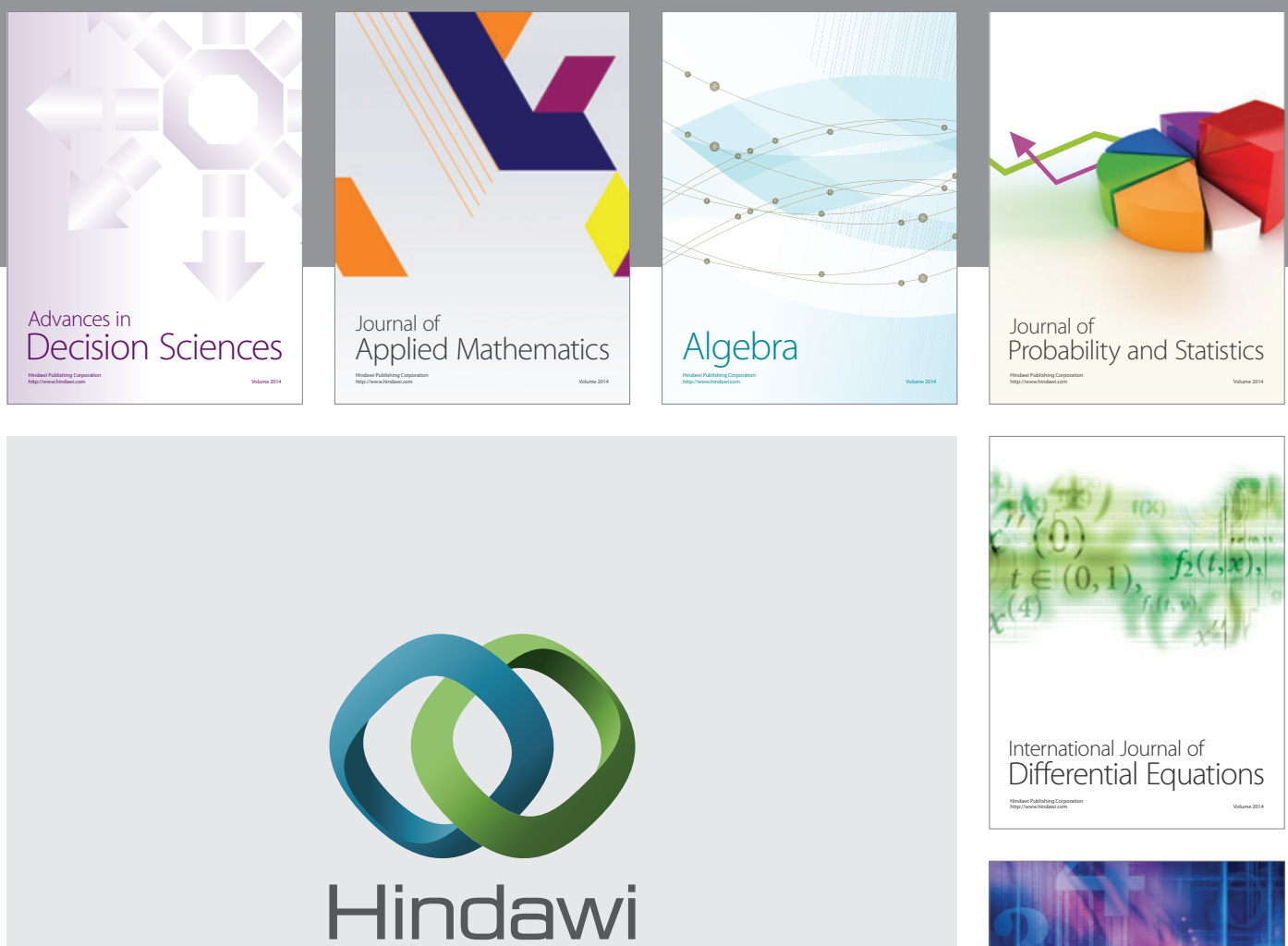

Submit your manuscripts at http://www.hindawi.com
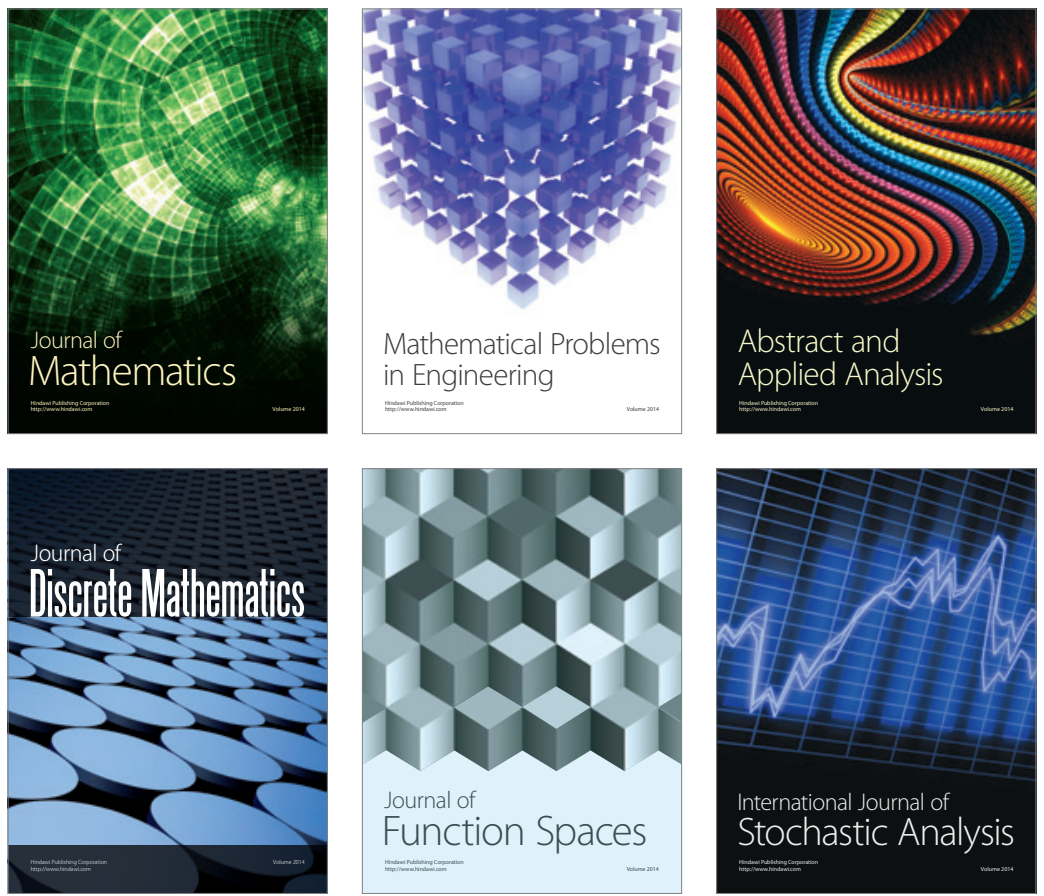

Journal of

Function Spaces

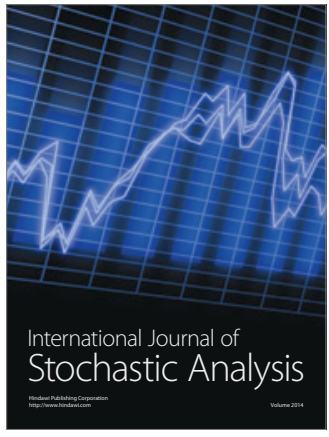

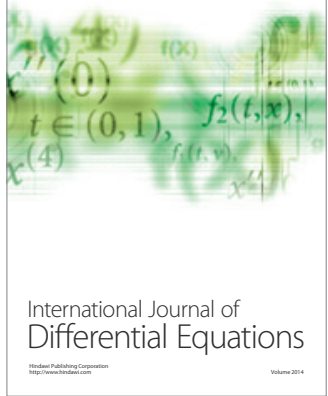
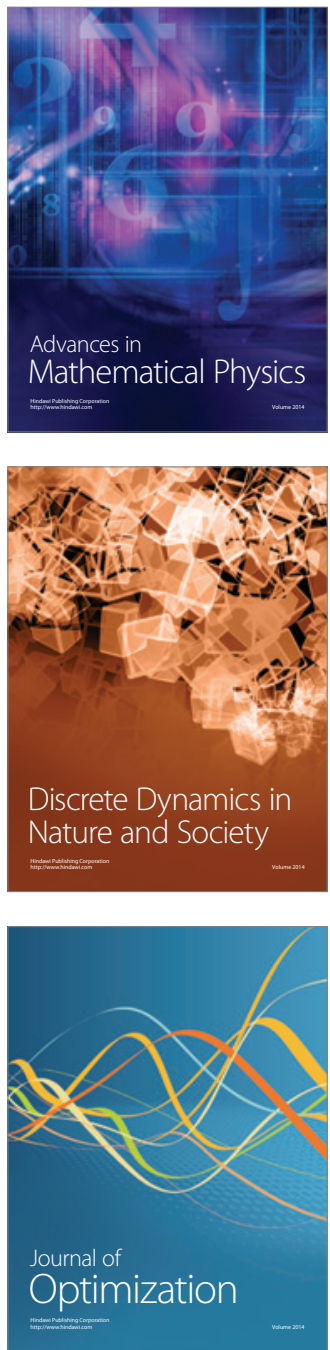